\title{
A Construction Management Framework for Mass Customisation in Traditional Construction
}

\author{
María Dolores Andújar-Montoya ${ }^{1, \uparrow}$, Virgilio Gilart-Iglesias ${ }^{2, \dagger, *}$, Andrés Montoyo ${ }^{3, \dagger}$ \\ and Diego Marcos-Jorquera ${ }^{2, \dagger}$
}

1 Department of Building and Urbanism, Polytechnic University College, University of Alicante, Carretera de San Vicente del Raspeig, s/n, 03690 Alicante, Spain; E-Mail: lola.andujar@ua.es

Department of Computer Science and Technologies, Polytechnic University College, University of Alicante, Carretera de San Vicente del Raspeig, s/n, 03690 Alicante, Spain; E-Mail: dmarcos@dtic.ua.es

3 Department of Software and Computing Systems, Polytechnic University College, University of Alicante, Carretera de San Vicente del Raspeig, s/n, 03690 Alicante, Spain; E-Mail: montoyo@dlsi.ua.es

$\dagger$ These authors contributed equally to this work.

* Author to whom correspondence should be addressed; E-Mail: vgilart@dtic.ua.es; Tel.: +34-965-903-400 (ext. 1307).

Academic Editor: Masa Noguchi

Received: 12 November 2014 / Accepted: 10 April 2015 / Published: 28 April 2015

\begin{abstract}
A Mass Customisation model is discussed as a competitive positioning strategy in the marketplace adding value to the customer's end-use. It includes the user as part of the construction process responding to the customer's demands and wishes. To the present day, almost all proposals for Mass Customisation have been focused on the design phase and single family houses. The reality is that the processes carried out in the work execution are so inefficient that the costs of the Mass Customisation models are assumed by the customer and they do not offer solutions that support the change management. Furthermore, this inefficiency often makes Mass Customisation unfeasible in terms of deadlines and site management. Therefore, the present proposal focuses on achieving the paradigm of Mass Customisation in the traditional residential construction complementary to the existing proposals in the design phase. All this through the proposal of a framework for the integral management in the work execution, which will address change management introduced by the users offering an efficient and productive model that reduces costs in the process. This model will focus on the synergy between different strategies, techniques and technologies
\end{abstract}


currently used in the construction management (such as Lean Construction or Six Sigma), together with, other strategies and technologies that have proven to be valid solutions in other fields (such as Business Process Management, Service Oriented Architecture, etc.).

Keywords: mass customisation; construction management; efficiency; change management; integration; BPM; Lean Construction; six sigma; SOA

\section{Introduction: Mass Customisation in Housing Market}

Mass Customisation is emerging as an inevitable strategy to ensure competitiveness in a customer-oriented market [1], this means to satisfy more closely the individual wants and needs of the customers, by providing a wide variety of options and individual customisation at prices comparable to standard goods [2]. So, mass customization is the capability to integrate these varieties derived from the individual customer's needs and the efficiency of standard mass production $[3,4]$. Specifically, in the Spanish housing sector the need of adopting competitive strategies oriented to the prospective buyer is more pronounced due to the current economic slowdown, the sharp drop in activity and the oversupply in dwelling that difficulty the home sales. The strong adjustment of the sector, the high number of dwellings in stock, the largest social requests from the future users and the increased normative requirements, especially in terms of sustainability, safety and quality in buildings, address companies to the imminent need of being reinforced to compete in the market [5]. Facing this new development, enterprises need to be positioned in the market through a differentiation with competitors by implementing new ways to add value to their offers [6]. Through the offer of Mass Customisation in the property development, value-added services are created replying to the need of some potential customers who are changing the way they used to buy, integrating customer into the process. So a new agile and flexible approach is needed not only to satisfy the initial customers' requirements, but also to provide a greater ability to adapt to their needs as they evolve [7] with the same cost as in mass production [8].

However, the barriers to achieving this approach in the field of building and construction are high. At the same time that enterprises are forced to react to the growing individualization of demand, the increased pressure of competitors and the financial conditions of the market dictate the need of shorter construction time, reduction in total costs and higher production quality. Companies must adopt strategies that include both cost efficiency and a closer relationship to the customer's needs [9]. This need of efficiency in building costs is one of the principal barriers to Mass Customisation, as it leads to increased material costs, higher manufacturing costs, lower on time deliveries, increased level of needed inventory for every variant of Customisation and reduction in product quality [1]. These increases in costs cannot be absorbed by customers who usually expect individualized products at the same price as they would pay for mass-produced items [10].

Besides the increase in cost, Mass Customisation accompanies problems related to term, due to the fact that identical houses cannot be produced. Construction firms require more time to carry out the site works for not being totally familiarity with the plans, owing the variability of them from some property to another [11]. 
Furthermore, Ph.D. Noguchi describes in "ZEMCH Research Initiatives: Mass Customisation and Sustainability" [12] the additional obstacles related to customisation in property developments, such as lack of pilot housing, more complexity in communication, greater chance of material delays, and disadvantages in negotiations with subcontractors.

Another obstacle attributed to the housing customisation is the delay in the buyer decision making, a fact that can cause delays in the planning of works [13]. Also the risk of doubtful customers and changes in opinion derived from the array of choices.

In addition, this flexibility and variability increase the complexity of the management and the execution of the whole process given that the diversity of options may exceed the capacity of the organization to manage works efficiently.

Currently, construction companies do not have information systems to address efficiently the management of Mass Customisation in site. This obstacle is compounded by the inefficiency in productivity indexes that has been dragging the industry in the last years, in comparison with other sectors of the Spanish economy.

Consequently of the foregoing and considering the current situation of low profit margins, the main barrier to adopt Mass Customisation in housing is the lack of a structured system to help the site management efficiently, minimizing the extra costs, the deviations in schedules, the materials delays and the uncertainty in the planning. Therefore, the short-term challenge for the industry is to increase efficiency by reducing these barriers at the same time the communication and negotiations are improved bringing simplicity to the management, and providing added value to the product.

This requires the adoption of a new management model that makes feasible Mass Customisation in property developments, allowing the satisfaction of the customer requirements, thus accentuating the competitive advantage of firms.

At the present time there are proposals with large repercussion to reinforce company competitiveness, and then overcome the main barriers to adopt the Mass Customisation. They are mainly centred on solving the inefficiency in cost and time of the construction works, while they focus on meeting the customers' needs. To develop and emphasize the competitive advantage of a corporation some construction companies are starting to carry out relevant business management strategies to strength their position in the market. One of the most emerging approach to improve organizational effectiveness is the application of Lean Philosophy [14] to construction, which is consider as a part of a "cost leadership [15]" competitive strategy [16] that maximize customer value while minimizing waste. Also another upward trend to increase productivity is the implementation of Information and Communication Technology (ICT) as a competitive approach that is increasingly being used in the construction industry [17]. Several options of specific software for the works are available to increase productivity in the construction process (e.g., software for quality control, planning, project based accounting, etc.). Also software tools of enterprise performance systems (ERP) or customer relationship management (CRM), among others, are implemented by many companies.

Therefore to exploit the whole potential of each specific proposal it should be approached in a holistic solution [18], avoiding the technological waste with the "point solutions" for each stage of the construction process and looking for a well-suited solution to construction [19,20]. Accordingly, to get a holistic solution in the site execution, the main novelty lies in using for the first time, Business Process Management (BPM) in construction, in particular to provide an integrated management model by using 
BPM as a backbone solution. BPM is an evolving trend in management science whose effectiveness has been commonly demonstrated in other fields such as the industry sector, banking, retail, government, and health care. The importance of BPM is confirmed by the existence of specialized international journals (e.g., the Business Process Management Journal), conferences (e.g., the Business Process Management Conference) and courses institutionalized at several universities [21]. This is a powerful instrument to gain competitive advantage through a holistic process-oriented view [22] based on the ICT to automate or support processes and their lifecycle. This holistic view can involve a lot of management disciplines and techniques (such as lean, Six Sigma, lean, ERP, Service Oriented Architecture SOA, and other enablers [23]) and embraces parts of management, like Change management, Information Technology (IT) management, Project management and deals with suppliers, customers, employees, etc... [22]. BPM is a comprehensive approach to process improvement and it is focused on integrating, aligning, managing and measuring all the business processes of an organization. It is an inclusive approach of other approaches, it includes the application of all the other available methods (Process Excellence, Performance Improvement, Six Sigma, Business Process Reengineering, Lean, Business Process Engineering, Customer Expectation Management) [24]. BPM is the synthesis and extension of several technologies and techniques into a unified whole, a new foundation upon which to build sustainable competitive advantage [25]. Therefore our proposal lies in an integrated solution that embraces all the earlier proposals that allow Mass Customisation, while provides continuous improvement, customer satisfaction and constructive sustainability.

The rest of the paper is structured in the following way: In Section 2 a review and analysis about the state of art of the research proposals and related works is done; in Section 3 the research methodology is explained; in Section 4 the problems and weaknesses associated with the current process are described; in Section 5 partial solutionsare presented and the integrated management model proposed; in Section 6 an use case implementation and validation is defined,and finally in Section 7, the main contributions and main conclusions of the research and the way forward for future research are presented.

\section{The State of the Art in Mass Customisation Applied to Construction Industry}

Nowadays, there are several proposals that suggest the implementation of Mass Customisation inside the construction industry. One of the most cited authors in the field, Ph.D. Masa Noguchi [26], highlights the importance of Mass Customisation in the industrialized housing as a marketing strategy to solve customer dissatisfaction inside the Asian real estate market. Noguchi focuses on resolving the customer dissatisfaction through various customisation options. By offering customers the opportunity to express their specific needs with a support system for decision making in customizing homes. Based on online information technologies, Noguchi's approach provides the necessary support, with the available solutions and the estimated costs of the choices. This option is only available for prefabricated homes, so what about the traditional construction? In this way, the author [11] also introduces the implementation of Mass Customisation in traditional construction projects, but this time the newness consists in the application of a communication system that allows users to take part in the customisation of their homes.

In the same way, other authors [27] suggest that customers are involved in their housing customisation through a support system for decision-making according to their preferences using a hybrid approach, that combines case-based reasoning (CBR) and genetic algorithm (GA). Through this system the 
possibility of customer dissatisfaction with the final product is reduced, solving the problems caused by inexperience for decision making cost-quality of the chosen option, or by discrepancies between expectations and final outcome of the house.

Also other researches [28] improve the customer participation by encouraging the exchange of information through an interactive models for customers that include BIM (Building Information Modelling) technology. With this approach they incentivize customer satisfaction while gaining the benefits of using BIM (Building Information Modelling) technology, as getting a better integration of data, fewer mistakes and inconsistencies in the projects. In addition to this, through the BIM system can be extracted 2D drawings and 3D models from any point of view, reducing time, work and mistakes that come from project modifications.

Although all these solutions improve customer satisfaction, giving them the opportunity to participate in the design process by customizing the house according to one's preferences, they provide a partial solution because customers are only involved in the design phase but they are not in the construction phase. So in none of them is proposed an integrated solution to the problems of efficiency in traditional construction.

Related to this another paper [29] presents an improvement, through the implementation of a production model that includes three sets, a design system, a construction system and a computer system, based on the codification of prefabricated building systems. The integration is achieved through a tool to visualize solutions and the automatic generation of the required information in the production phase. They present an integral system based on technology that speeds up the construction process while providing customer satisfaction, without increased cost. Nevertheless they offer a partial solution because it is only oriented to a prefabrication business model and actually not in traditional construction. In addition, it is only available for a modular design. Also the building system outlined in the paper follows a procedure not a customer oriented process. It is not process oriented and there is a delinking between process and technology.

As well, some authors [30] propose the use of technology to overcome the disadvantages arising from the Mass Customisation, such us increased manufacturing cost, fewer on-time deliveries, low supplier delivery performance, and increased order response time, increased material costs and reduction in product quality. To reduce these shortcomings and the bad influence on the construction costs they use information technology (IT) to give speed to the process, accessibility and exchange of information. By the use of a system called FIS-Finishing Information System, they improve the productivity in housing construction, minimizing the additional manpower due to the use of Mass Customisation, improving the efficiency of communication between providers and consumers, even if the process participants are geographically separated.

Although the proposal demonstrates the adequacy of Information Technology (IT), it is thus important to note that it is not focused on process management or the continuous improvement processes, neither are they measured. In addition to this there aren't defined actors and the functionalities are not established.

Despite all the literature reviewed for Mass Customisation applied to construction, the mostly analysed solutions focus their interest on the design phase. Thus, they do not do in the site execution phase. Also hardly any of them are centred on a technological solution. And the ones that take advantage of ICT's do not offer an integral management system to solve the problems that impede to achieve Mass Customisation in the field, such as the lack of business strategies that allow better efficiency in operations and people involved in them using technology holistically. 


\section{Research Methodology}

Based on the analysis performed in the previous sections, it has been identified the need to propose a comprehensive model for the execution of the works oriented towards mass customisation. It allows achieving a strategic position in the market and satisfying customer needs by adding value to the product. At the same time, the necessary requirements to achieve this model were identified, obtained from observation, experience and analogy to other areas where similar problems have occurred. The synergy between the different management strategies, that are identified, together with ICTs will be the key factor to achieve these requirements.

To carry out the proposal it has been followed a research methodology based on business process management [31-33]. Process management is a strategy for structuring a complex process into a sequence of tasks understood as actions that transform inputs into some other output elements. This transformation must be aligned with previously defined goals, which are considered as strategic, to meet some needs or gaps identified in the environment. In this way, the defined process will achieve the object model of this work in a systematic way, selecting the most appropriate techniques and tools to meet the objectives and thus solving the problems identified. In the proposed methodology, each of the tasks identified represents a stage of the investigation, and these will have associated one or more scientific methods as described below.

The proposed research methodology is based on Eriksson-Penker formal notation [34]. It is an extension of UML for the representation of business processes that is characterized for being very intuitive and easily understood by all the stakeholders involved in the process. This is a notation that facilitates the understanding of the problem and its subsequent analysis to identify a solution according to the objectives.

Specifically, from the starting hypothesis Figure 1 shows the main process carried out in the research, where the input element $(<<$ input $>>$ ) represents current models of mass construction. This $<<$ input $>>$ must be transformed through this design process into a building model oriented towards mass customization $(<<$ output $>>)$, meeting the requirements identified above and which now represent the strategic objectives that will guide the research process $(<<$ goals $>>)$.

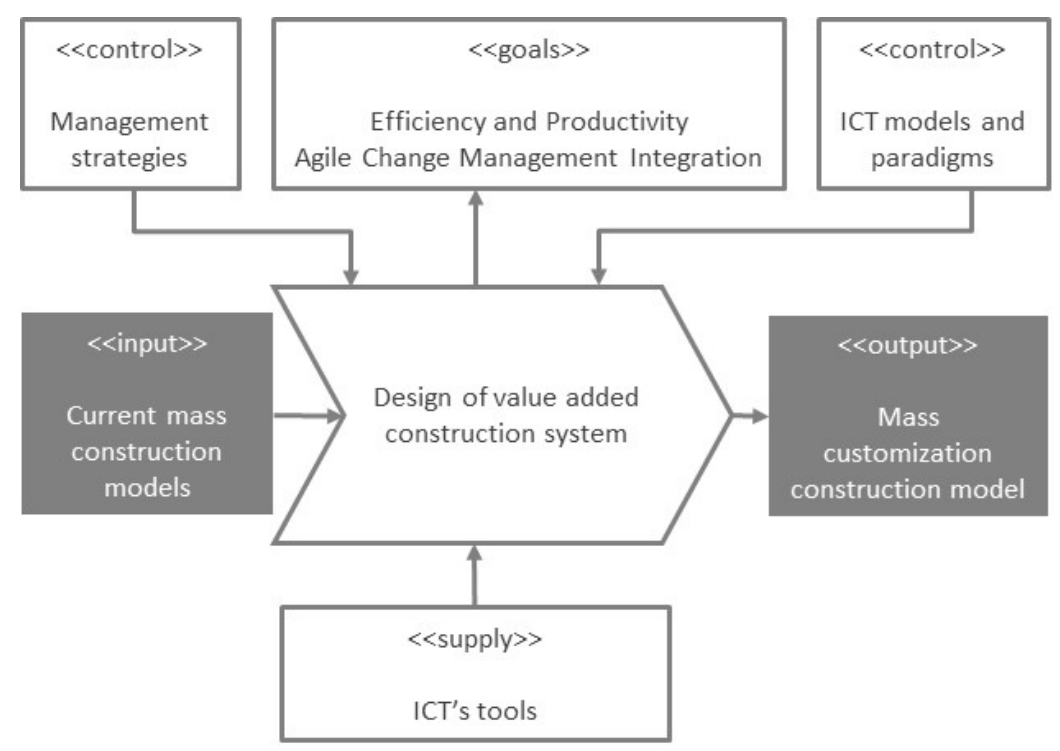

Figure 1. Modelling of value added design construction system process through Eriksson-Penker notation. 
To perform the transformation to achieve the objectives established, must be identified the controllers $(<<$ Control $>>)$ and facilitators $(<<$ supply $>>)$ needed to guide this transformation. Particularly, these elements represent strategies, paradigms, techniques and technologies that will be integrated into our proposal. To facilitate its identification from a better comprehension of the problem, processes can be divided into sub processes or tasks. In our case a first division has been required as illustrated in Figure 2.

The resulting sub processes are, in first place, the sub process "identification of the construction site problems", focused on locate those general problems of mass construction current models that impede the achievement of the goals of the main process. In second place the sub process "partial solutions analysis", centered on the identification and analysis of solutions to the problems identified in the previous sub process. And finally, the sub process "integration of solutions" focused on obtaining an integral solution to the problem.

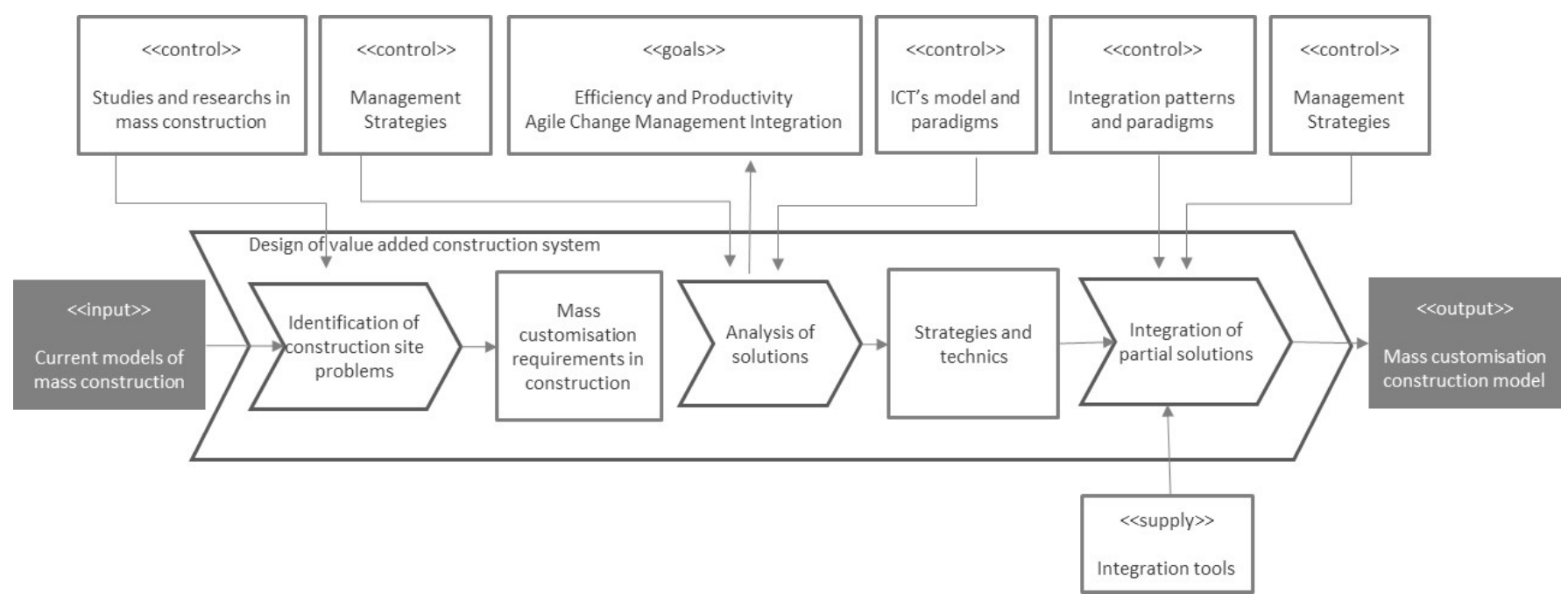

Figure 2. Modelling of value added design construction system sub processes through Eriksson-Penker notation.

In the following sections and using this methodology, will be developed each mentioned sub process, justifying the achievement of the general and particular goals and describing the actions performed to obtain the proposed model.

\section{The Analysis of the Construction Site Problems}

As we have specified before, one of the main barriers for adopting Mass Customisation as a competitive strategy in the sector is the increase in uncertainty, complexity, cost and time. These inconveniences are further compounded by the already low standards of efficiency and productivity that the sector is dragging in recent years. Compared with the traditional manufacturing industry, the construction sector has a 30\% of less productivity levels [35] even though it sets up as a key sector within the framework of the Spanish economy. It reached at its peak the $11 \%$ of Spanish Gross Domestic Product GDP [36]. 


\subsection{Identifying the Causes of Such Problems}

These shortcomings in productivity and efficiency levels produce a significant increase in construction costs, due mainly to some causes that have their origin in the business organization such us obsolete management models, lack of business integration, improvisation in strategic decisions or search for short-term benefit. Some of them are a result of the real estate boom experienced by companies during the housing bubble [35]. Therefore, to be successful, the construction companies need to supplement their current short term approaches with more long term strategies $[37,38]$ and move from traditional models management to advanced models management, based on the inter-and intra-enterprise integration [39] that respond to the new situation of the sector. Through better business integration and organizational structured models it is possible to take full advantage of functional synergies and reduce costs. With a systematic organization structure that takes into account the capabilities of stakeholders and the environment, avoiding making decisions by relying exclusively on intuition or experience.

Besides the business causes that promote low levels of productivity, mostly of the problems come from people who participate in the process. The construction works are characterized by the concurrence of variety of firms and participants. These problems appear mainly in two kind of agents: Contractors-subcontractors and workmanship [40]. On the one hand, they talk about the necessity of eliminating the adversity and competition atmosphere, that it is usually generated because of the war costs generated between subcontractors and their low involvement in the project. On the other hand, they point the low level of specialization and experience of the sector's manpower. Also they stipulate that the successful key is to become the adversity tendency between different parties, in adaptations and collaborations for mutual success, and to implement security and training oriented programs for all the workers. Related to the lack of formation also it can be included as human causes the unstructured traditional works prone to improvisation, without a systematized procedure [41]. Besides to this, they state the human causes that promote low productivity as lack of involvement, poor worker performance, low motivation, absenteeism, turnover and changes in the work teams, insufficient space to do their jobs efficiently, and the presence of obstacles in workspaces. There are also quite frequent incidents during the course of the construction works, such as project changes during execution, design errors and re-works made by the repetition of activities badly performed [42].

As all they have suggested, the human causes have a huge impact in productivity. Furthermore this situation worsens because of the heavy dependence of the building sector on human resources rather than adopting advanced or automated technology [43].

Although technology is one of the greatest allies of the construction companies to improve the competitiveness of their business, the specific software for business management does not have much presence in the sector. Indeed, the large majority of the construction micro-enterprises $(97.9 \%)$ do not have ERP software tools [44]. Furthermore, the ones that use them show up a technological waste because the ERP package can hardly meet the needs of the construction industry[45] because they come from another sector. Due to its manufacturing origin, none of the construction management modules of commercial ERP packages provided by software suppliers have been found suitable for construction firms [46].

Then also, the main technological trend in the sector is the use of management software focused only on specific tasks such as project planning and monitoring, cost control, risk management, scheduling, etc. [47]. Also the whole process is divided into many isolated stages such as design, tender, construction, 
and maintenance, so the software applications used in each stage has led to the creation of "islands of automation", i.e., incompatible hardware and software, because of the lack of attention given to the integration of these applications [48].

This fact favours the tightness of information, impeding information being transferred from one stage to another [49]. Besides this and related to the incompatibility problem mentioned earlier, there is a technological gap because of the lack of a standardised platform for information exchange that can facilitate the flow of information between incompatible hardware and software [50]. This technological gap promotes the existence of errors due to the inadequate, incomplete and outdated information that usually lead to delays and extra costs during the execution of a construction project [51]. About these extra time and cost of operations, in [52] is emphasised the current lack of discipline in planning and execution tasks, due to the flow variation that increases operating cycle times. And in this sense, it makes worse the coordination of interdependent disciplines or crafts with the consequent unneeded inventory or lack of materials that produce incompletions tasks, and again, errors requiring work to be redone and re-handly. As well there are other factors that also cause missed deadlines and increased cost because of the uncertainty in the building construction, and the shortage of tools to address this uncertainty and these changes in a flexible manner. Change is inherent in construction works [53] due to some peculiarities such as complexity and uncertainty [54] resulting from one-of-a-kind nature of projects, the production site, and the temporary multi-organization [55].

\subsection{The Classification of the Causes}

Following the Leavitt [56] model classification the main factors involved in an organization and their interaction are distinguished. After that, it has been made a classification of the causes in order to help to identify the solutions. Then, all the previous causes that promote uncertainty, complexity, and deviations in cost and time, have been encompassed in four mainly groups of factors: Causes that have its origin in the structure or business organization, causes that have its origin in people who participates in the hole construction process, causes that have its origin in the applied technology and causes that have its origin in the tasks of the process.

Furthermore these causes are aggravated on account of the lack of integration and interaction, hampering the improvement of competitiveness in construction. This interdependence is shown in some researches [51,57] where is stablished the four interacting components that make up an organization (task, structure, people and technology) and how the change in one them inevitably affect the other three. This synergy implies that major improvements are made by house building companies by focusing on all the interrelated actions areas.

Therefore to reach the paradigm of Mass Customisation in building is necessary a comprehensive model that solves the requirements defined in Figure 3. To solve these causes is need competitive essential actions such as a change of mind, a shift toward process orientation and improved communications [51]. By encouraging better communication intra (inside organization level) and inter (customers-subcontractors and suppliers) companies with cohesive relationships based on trust, mutual commitment, understanding of each other's individual expectations and an open book culture (open exchange of information), organizations remove problems about information and the bottleneck that can lead to delays and extra costs. Also some key drivers of change to solve problems of cost and time are: 
Committed leadership, a focus on the customer, integrated processes and teams, a quality driven agenda and commitment to people. This last one also includes decent site conditions, care for the health and safety of the work force, including commitment to training for all participants in the process, involving everyone in sustained improvement and learning [58].

In this regard, some of the current new paradigms or technological solutions to achieve construction efficiency are only sub optimizing individual factors instead of optimizing the entire system [59]. Then, the expected benefits are not achieved because there is not a strategic vision in the organization or technology do not form an integral part of the organization business strategy [60]. Then, the appropriate way of implementing changes and innovation is enhancing the overall organizational performance [61], emphasizing a holistic model that includes innovation in business strategy, organization of work, technology, and people. So to take full advantage of functional synergies, changes cannot be done in isolation, it is necessary to develop a holistic system where the factors, structure, tasks, people and technology, are linked (Figure 4).

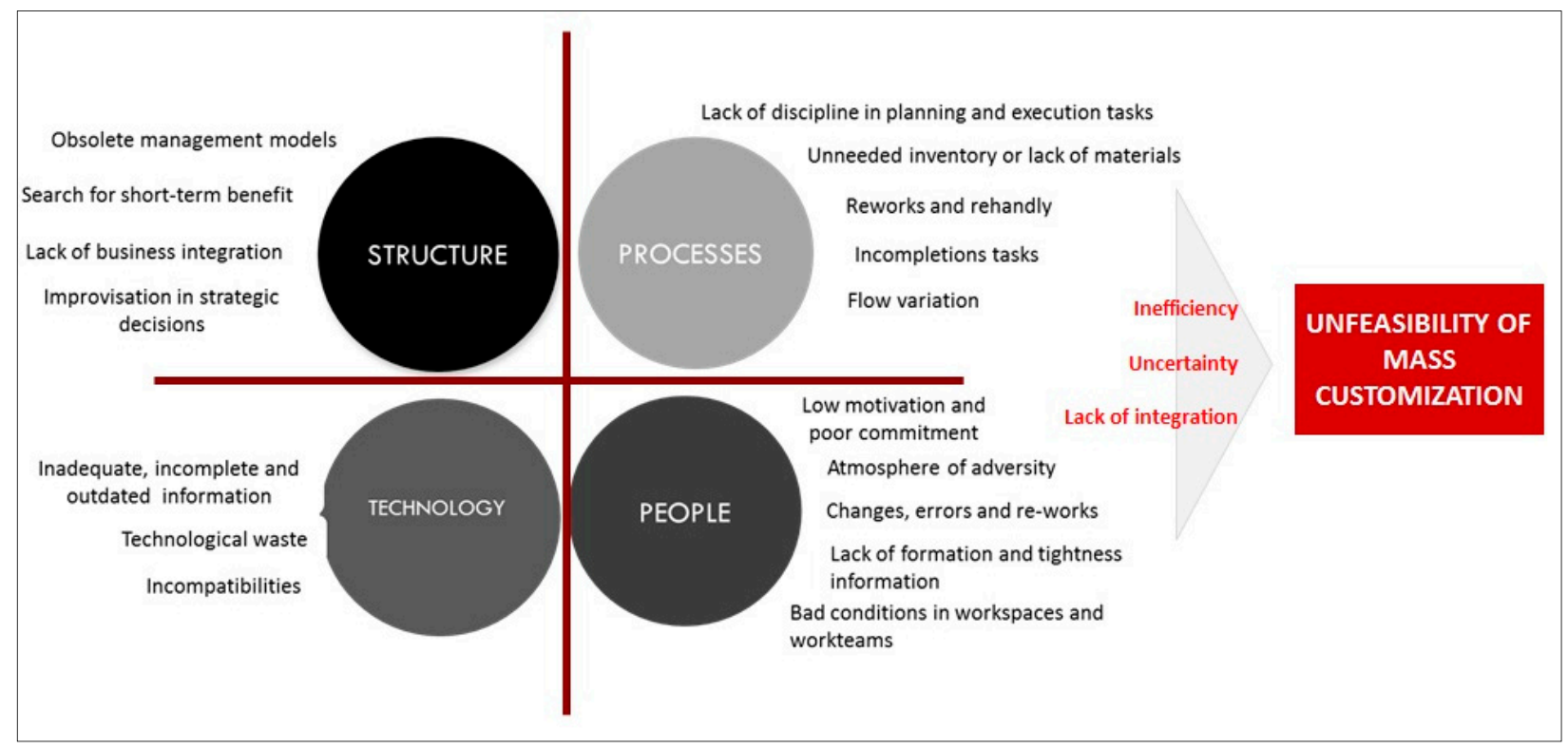

Figure 3. The Classification of Causes.

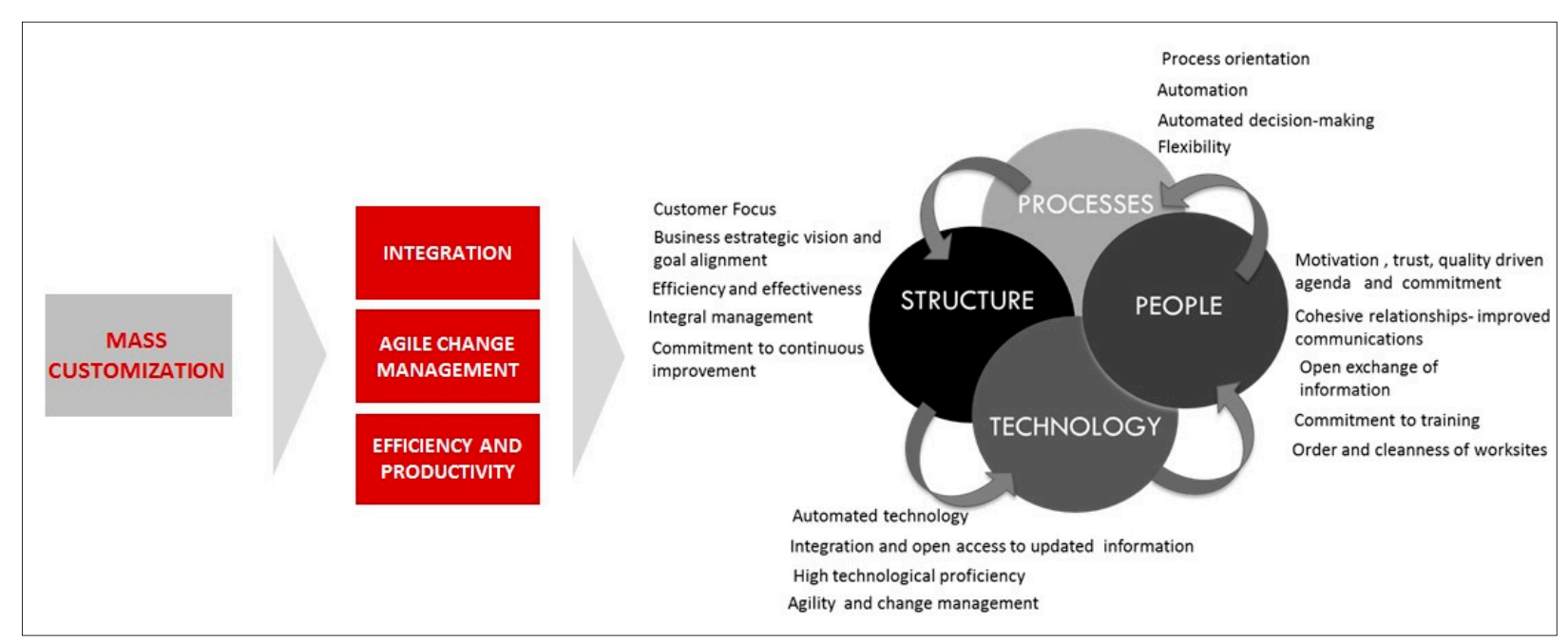

Figure 4. Requirements for Mass Customisation Feasibility. 


\section{An Integral Management Model for the Works Execution Oriented towards Mass Customisation}

Within the construction field, there are different novel proposals that are focused on some of the objectives identified above. However, it comes to independent and partial solutions that do not offer an integral solution, which contains wholly the above objectives (Table 1). Therefore, a general and integral model it is proposed to achieve new paradigms, like Mass Customisation, in construction. The proposal is based on the integration of the above solutions, which offer partial solutions to the considered problem, together with other proposals that have proven successful in other sectors to solve the rest of problems that impede achieving Mass Customisation.

Table 1. Objectives Achieved with the Existing Techniques.

\begin{tabular}{|c|c|c|c|c|c|c|c|c|c|c|c|c|c|c|c|}
\hline \multirow[b]{2}{*}{ Existing techniques } & \multicolumn{15}{|c|}{ Objectives Achieved with the Existing Techniques } \\
\hline & 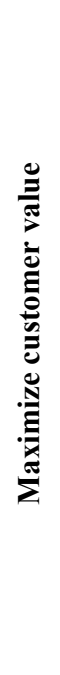 & 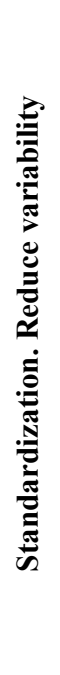 & 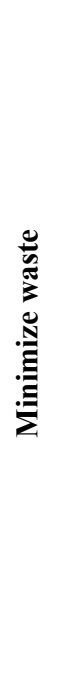 & 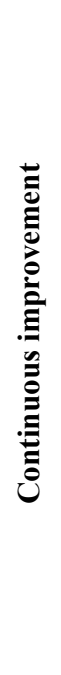 & 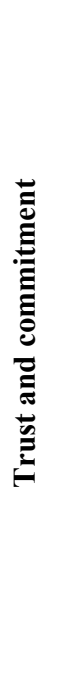 & 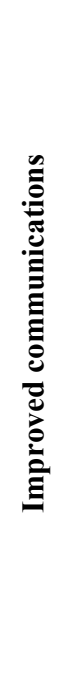 & 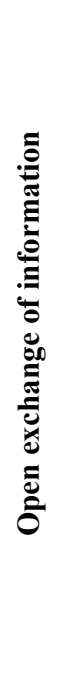 & 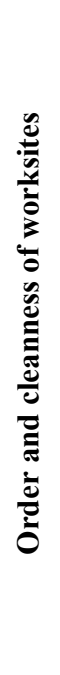 & 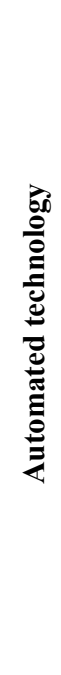 & 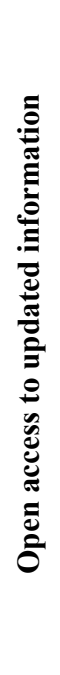 & 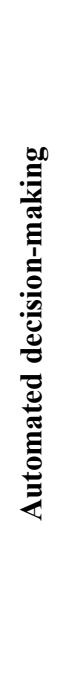 & 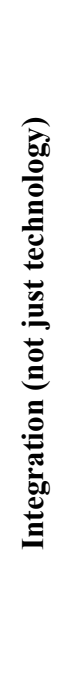 & 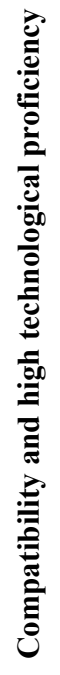 & 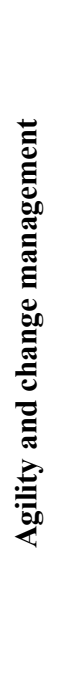 & 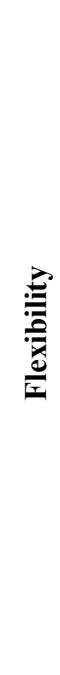 \\
\hline Lean Construction & - & ! & - & घ & - & - & - & - & & & & & & & \\
\hline Six Sigma & घ & ! & & - & ! & & ! & & & ! & & & & & \\
\hline ICT's & & & & & & & & & घ & a & घ & & & & \\
\hline BPM & घ & घ & घ & घ & & - & - & & a & a & घ & घ & घ & घ & ! \\
\hline
\end{tabular}

One of the emerging mainstream approaches in the construction industry is the application of the Lean Construction philosophy, the new form of production management that comes from the manufacturing industry [14].

The aim of Lean Construction is to reconceptualise construction as flows to maximize customer value while minimizing waste, understanding waste [62] as any activity which absorbs resources but creates no value, such as mistakes which require rectification, processing steps which are not actually needed, movements of employees and transport of goods from one place to another without any purpose, groups of people in a downstream activity standing around waiting because an upstream activity has not delivered on time. Thus, Lean helps the firm to define customer value focusing on activities that add value, through standardizing the types of waste and offering best practices to remove waste. And therefore achieving, among other things, to reduce inventory and waiting times [63]. In addition, as it is established by Professor L. Koskela [54,55] other main focus of Lean Construction is to increase output value through systematic consideration of customer requirements, to reduce the cycle time, to simplify 
by minimizing the number of steps, parts and linkages, to increase output flexibility, to increase process transparency, to focus control on the complete process, to build continuous improvement into the process, to balance flow improvement with conversion improvement and benchmark, and to reduce variability. Understanding as variability the construction uncertainties that produce late delivery of material and equipment, design errors, change orders, equipment breakdowns, tool malfunctions, improper crew utilization, labour strikes, environmental effects, accidents, and physical demands of work [64], to eliminate these variations and create workflow in a process is widely recognized the use of the LSS method [65]. Six Sigma is a statistical-based methodology that provides a structured framework to organize and implement strategic process improvement initiatives to attain reductions in process variability [66]. Within the construction industry, Six Sigma has been applied independently to improve the overall performance by reducing process variability in current construction operations [67]. Moreover it has been implemented as a quality initiative in traditional construction [68], increasing customer satisfaction and profitability by improving the quality of products [69]. Also it has been used for sustainability and quality improvement in prefabricated composite structures, applying Six Sigma to increase quality management while reducing the consumption of energy during construction, pollution, noise pollutions and waste [70]. Similarly, to reduce and eliminate waste in prefabricated residential construction, Lean principles and Six Sigma has been used by working in unison as an integrated model [71]. This combination of Lean tools and Six Sigma has been also applied in traditional construction, where each methodology complements the other, to eliminate waste and variations and create workflow $[72,73]$. Lean does not possess the tools to reduce variation and bring a process under statistical control, and in the same way, despite the fact Six Sigma offers a lot of gains alone the process would be slow and its costs will be too high. More specifically, lean benefit Six Sigma in the identification of waste providing the powerful value stream map tool that highlight waste and delays, while improve process speed or cycle time [74].

Despite the common factors and the synergy benefit, Lean mainly revolves about the relation between people and process but it does not on technology [75], in a similar way the use of IT in Six Sigma projects is often carry out with specific statistical software [76]. Therefore, despite the benefits obtained in the use of LSS, it is not resolved the gap in terms of integration with the other factors identified above technology, structure, people and structure.

Furthermore, the introduction of these paradigms requires a great effort of change in thought and culture, in most cases made up for a change agent to facilitate its immersion[30]. There are other issues that do not cover the integration and agility to manage change. ICT misguided (BPR) can be counterproductive for achieving integration and agility (bottom-up approach).

Moreover, ICT's are presented as an indispensable facilitators that can help to achieve mass customisation in construction, by addressing some of the goals that have not been resolved by earlier paradigms such as the process automation, the technology integration, the support in decision making, etc. [77].

In other traditional sectors, there are now some proposals to implement strategies such as mass customisation [31], by using a set of paradigms and technologies oriented to solve some of the main obstacles that hamper the application in the construction industry.

These paradigms and technologies are focused on getting flexible systems that allow adapting quickly the technology to the business processes of an organization, by proposing fully interoperable open 
systems (such as Service Oriented Architecture SOA, Web Services and Restful or Enterprise Service Bus) [78-80].

In addition, they consider the reuse of legacy systems like the ones used today in construction, the implementation of which has involved high cost and should not be discarded if not transformed into elements with the necessary functionality to support the processes of the organization.

Also the use of intelligent techniques based on semantic reasoning have brought great benefits to achieve mass customisation, enabling the automation of certain management steps like modelling (such as ontologies and associated techniques) [33].

\section{BPM as the Backbone}

To meet the stated goals, it is necessary to join these views or partial solutions because when the integration is done properly, the benefits provided individually will be increased [71,72,81]. For this it is necessary to achieve the integration of all the factors and resources involved in the execution of the work. And also to be able to reach an agile change management, allowing the immediate alignment between the strategic objectives, the defined business processes to achieve those objectives and the technologies that support the execution of the processes.

In this sense as the main novelty to cover these gaps, it is proposed the strategy Business Process Management (BPM) [82] to support the model which not only allows achieving those goals, but also enhancing the benefits obtained by the other proposals such as efficiency, productivity and agility (Figure 5).

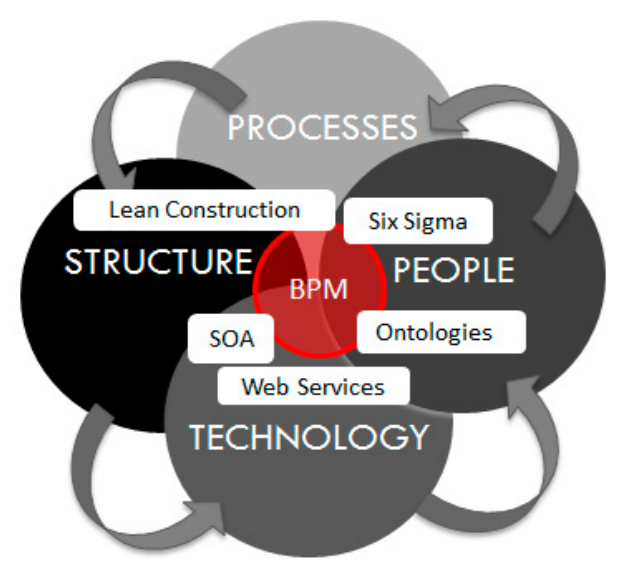

Figure 5. BPM as the Backbone of the Four Interacting Factors in Organizations.

BPM is a process-oriented business strategy focused on continuous improvement which includes IT as a fundamental element, unlike other strategies, filling the gap between business needs and IT capabilities [83], managing the complexity of the diverse inherited technology portfolio, creating transparency in the business environment and creating the agile link between business strategy and its execution [84]. All this is achieved in form of a continuous process management lifecycle [85], consisting of discovery, design, implementation, deployment, execution, interaction, control monitoring, analysis and optimization phases.

Associated to the BPM movement has emerged a software solution focused on process management that supports the principles and the BPM lifecycle model, allowing the integration of people, systems and 
suppliers, the automation and the processes collaboration. They are called the BPMS (Business Process Management System or Suite) [86]. The technological components linked to this system are shown in Figure $6[25,82]$ and they are what give its key features and benefits: Monitoring and control the information of the key performance indicators process, to reduce costs by automating and improving processes in real time, to adapt processes to changes in an agile way, immediate deployment of process-centric applications, to carry out solutions that face up to the needs resulting from continuous change, and use the investments in existing IT.

Taking as reference the BPM paradigm, whose life cycle will be supported by a BPMS system, the benefits of the solutions presented individually will increase [66,71,81]. The presented model is structured according to the top-down strategy by providing two levels, the level of management and the level of resources respectively, which will be connected through the BPM system (Figure 4). This approach is important because to achieve the proposed objectives it is necessary a complete understanding of the processes before being automated.

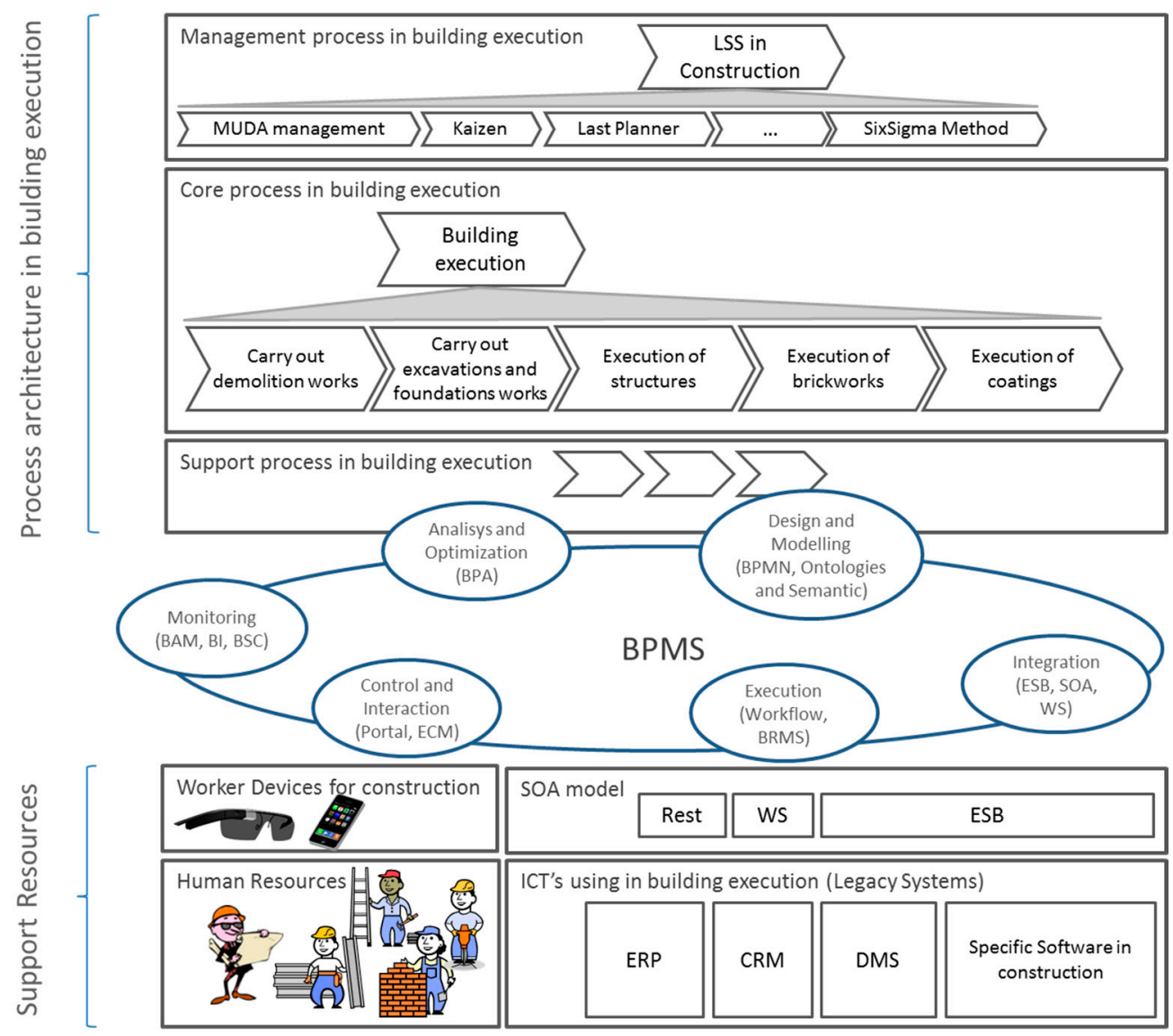

Figure 6. A Construction Management Framework for Mass Customisation in Traditional Building.

At the management level it is placed the work execution process architecture including process flow, the objectives to be achieved, the key performance indicators (KPIs) associated with the objectives of achievement measures, and the different stakeholders.

The BPMS includes tools for modelling and to include the elements defined in the architecture. The processes are modelled using BPMN standard notation, specifying in each process or task how to calculate KPIs and where to get the data, and associating the actors that should or may perform the 
different tasks to the BPMN model. BPMN is the standard notation for process modelling and that at any BPMS has a direct translation to the format that supports the processes execution, workflows owners or based on standards such as BPEL, BPEL4People and WS-HumanTask. Also BPMN is an understandable and intuitive notation based on flow charts, with a high degree of expressiveness that allows the process participants to understand how they should perform the tasks. The BPMS will support the processes included in this architecture that have been structured into three types, following any of the recommendations from some of the main authors $[23,25,87]$ processes management, core and support processes.

A key aspect of the proposed model is that it has been included within the layer of management processes the ones related to Lean Construction philosophies, Six Sigma in construction or LSS in construction that are focused on the processes efficiency of the organization. Specifically, are implemented as processes and procedures the different techniques and principles associated with these disciplines, such as Kaizen, Last planner system, statistical techniques or any other analysis technique for continuous improvement.

One of the problems identified in the application of Lean and Six Sigma in the construction environment is the difficulty to assimilate the implementation of these philosophies, due to their high cultural dependence [30]. The automation of these principles and techniques with tools related to BPM will help to facilitate the inclusion. BPMS includes process execution engines and incorporates task managers that show the work to be done by each actor according to the running of the process flow, storing the relevant information and disposing of it in real time anytime and anywhere. Not only will this help to accelerate the process but also to know what to do, how, when, and how long (standardization of Lean) to each participant, both in terms of production processes and to apply continuous improvement techniques for the government of such processes.

For example, the site manager will be guided by the Last Planner process to manage daily in an agile manner the project execution, assigning tasks every day and even changing that assignment, appearing instantly to every member of the affected team the process to perform, how and when. If a construction's worker has allocated the paving execution of the houses on the first floor and each customer have chosen a different kind of pavement, in each case, it would appear the correct custom process that the worker should follow for put it in the more efficient manner, as well as the estimated time (tacktime in Lean). Finally, when he would have finished the task, would conclude the work indicating the completion of the task, and then, the time spent on it and the materials used would be recorded. This could lead to a request for material purchase depending on stock and needs, or a process improvement analysis if the time spent were far above the tacktime. Even, any worker could throw a proposal for improvement initiating the Kaizen process to analyse the proposal and carry it out.

In the layer of core processes y support processes will be located the associated production processes of the value chain in the building execution and the processes that support the achievement of them, respectively. These processes will be designed according to the principles and techniques of Lean Six Sigma and BPM as it is shown in some studies [24,81] applied to the construction peculiarities. For example, standard processes based on the main guidelines and recommendations in the building execution field must be created to achieve greater efficiency.

However, in contrast to what happened with the BPR paradigm, it is not about getting fixed and inflexible processes but rather the proposed model will include the variability among its principles, allowing in an agile way to adapt the processes to the specific objectives of the organization and its 
continuous change through composition techniques included in BPM and related technologies like SOA and Web Services [78-80].

A further key and innovative aspect of the proposed model is the use of ontologies and semantic reasoners to streamline the generation of process modelling for the work execution. This issue directly affects the customisation efficiency, now that depending on customers choices, the appropriate processes to build the custom home will be generated connecting sub processes as if it were a puzzle. These processes will guide the work of other staff to avoid errors. These processes will be executed over the process engine or BPMS workflow, but to execute certain tasks or sub processes they must interact with external information systems that were presented as functional isolated islands within an organization, performing functions inside the process of the work execution. These systems are located in the resource layer of the model (Figure 6) and they will be exposed following the principles of SOA paradigm using Web Services technologies or ESB infrastructures.

In this way is removed the stiffness of these systems and their functionalities, providing aspects such as reusability, interoperability and alignment with business processes that increase the efficiency of the model. And thus, to take advantage of the existing resources which have been a high cost for the organization. The BMPs include an integration module that allows these technologies to interoperate perfectly. In fact, although BPM and SOA have emerged as two independent approaches, today we have tested the benefit of the joint use of both philosophies. Another essential element in the model is the staff, which is directly involved in the process of building execution.

BPMS provides several technologies that can be integrated into these processes. Firstly, technologies such as portals or ECM will allow different roles to perform several tasks associated with the process managing or human tasks that are a part of the process itself, as the buyer of the material. For it, it is proposed in the model the use of appropriate devices for the site features, where the use of devices such as mobile devices or google glass can be great allies.

Finally, the BPMS includes a model that offers different technologies allowing the process performance measuring in real-time, and the variability of the results through the KPI's defined. For the first case, this is where may be used Lean Construction techniques that would imply an improvement of the process. These indicators can be analysed manually by the person responsible, and this imply to throw one of the continuous improvement processes or may generate the execution of other processes to correct automatically possible deviations, as the application of material required. Another example would indicate when certain tasks are being diverted from planned tacktime.

In the second case, the indicators would be generated using statistical methods Six Sigma to locate deviations in the result of processes, such as e.g., the execution of the interior woodwork. If abnormalities were detected, process would be launched immediately to analyse the causes and propose possible solutions. This would allow us to reduce the work performed during the realization of the processes of finished works.

\section{Use Case, Implementation and Validation}

The theory model obtained previously presents an ambitious proposal in a framework that serves as a reference for the integral management for the execution of the works orientated to the achievement of mass customisation. The development of this model is to obtain a realistic proposal will be realized in 
different self-contained phases that by themselves contribute to achieving the efficient objectives and productivity and agile change management and integration. In concrete, in the present article it has been developed one use case of which the objective is the implementation of some representative techniques and principles defined in the model which permit reaching the strategic goals proposed. This relation is shown in Figure 7.

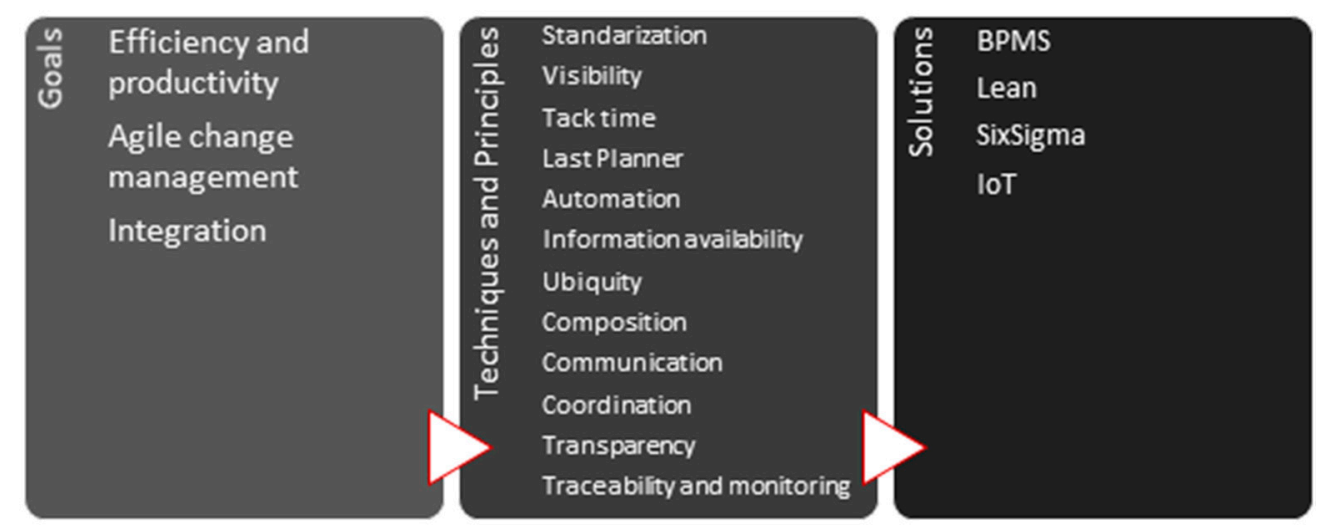

Figure 7. Relationship between objectives, principles and techniques and solutions.

In concrete, the use case includes two types of processes widely related, the process of weekly planning which implements the phase of the short-term planning of the Last Planner and which is located in the layer of management and the process of flooring, located in the layer core processes. Both processes have been chosen because of its repercussion in the mass customisation. The final customers could choose diverse types of floor and this includes that some customers could choose several types of floor for different rooms inside their houses. Also, this situation gets complicated and makes planning difficult because it requires a very high level of knowledge and control about the state of the execution of the works, concretely regarding the access of real time to this information because it exists too much variability and heterogeneity and human errors could increase considerably and therefore, increases the costs of execution and delays delivery deadlines laid out. On the other hand, it is possible that it is not known all of the proper procedures for each option of flooring or passing from one to another in a short period of time could derive in the inanition of some the steps.

Last Planner is a new technique of planning, used in Lean Construction that has broadly demonstrated its benefits in relation with efficiency and productivity. Nevertheless this is a complex process which implies a systematic methodology and a high level of coordination between the Construction Company and the different subcontractors. Also the information of planning carried out is realised in an extensive murals on the wall with the use of sticky's, which this information should be consulted in person. The election of the floor process has been because of different reasons. The flooring in a mass customisation model is a complex task due to the variability of the types of floor and therefore, to different procedures used for its execution.

The use of BPM as a management strategy to integrate other solutions has increased the benefits provided individually. In this sense, the use case was performed using the BPM open source Bonita BPM system (version 3.8). Firstly it has been done the modeling of the mentioned processes by using the standard modeling of business processes called BPMN (Figures 8 and 9). 

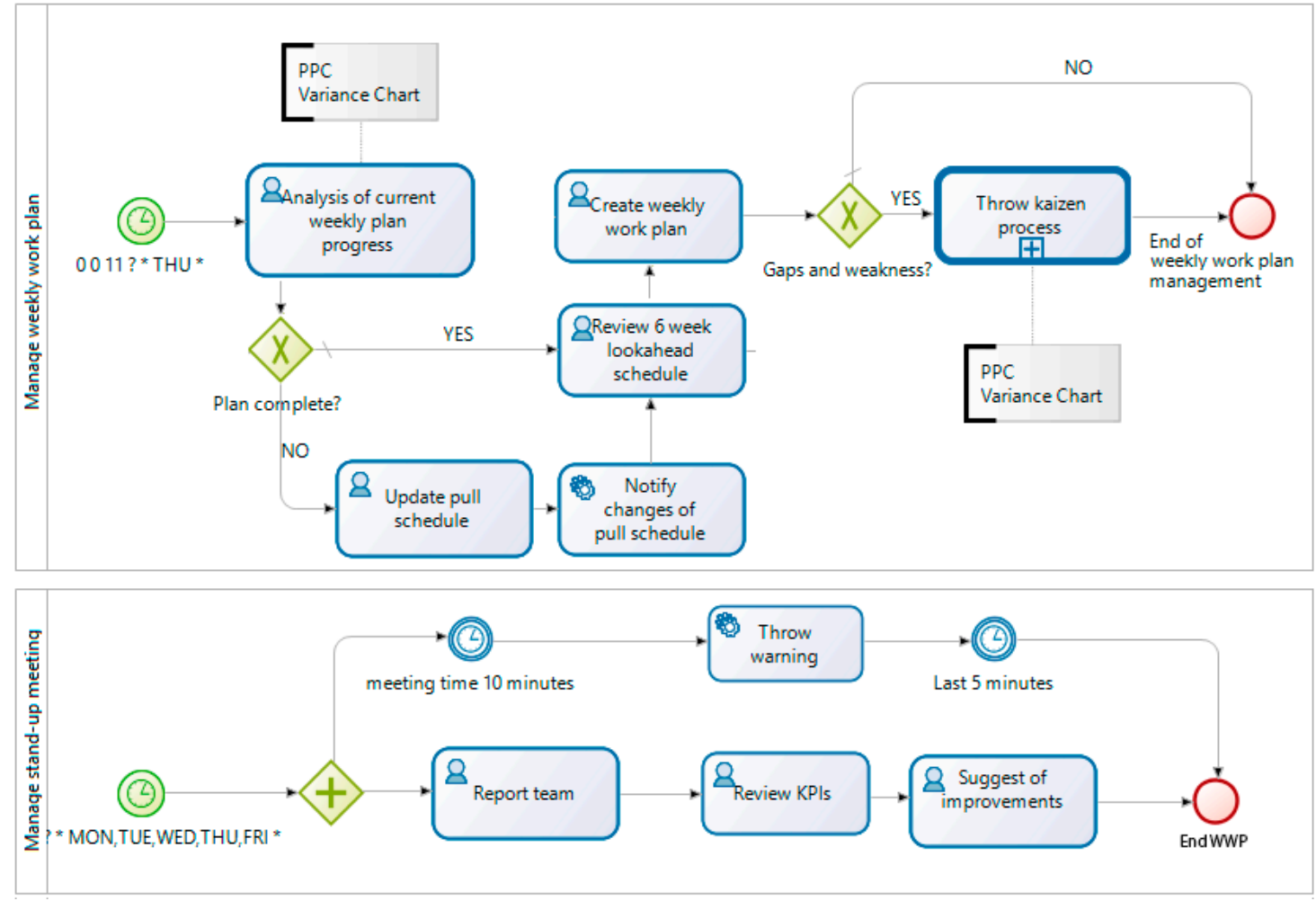

Figure 8. Weekly Work Plan BPMN model.

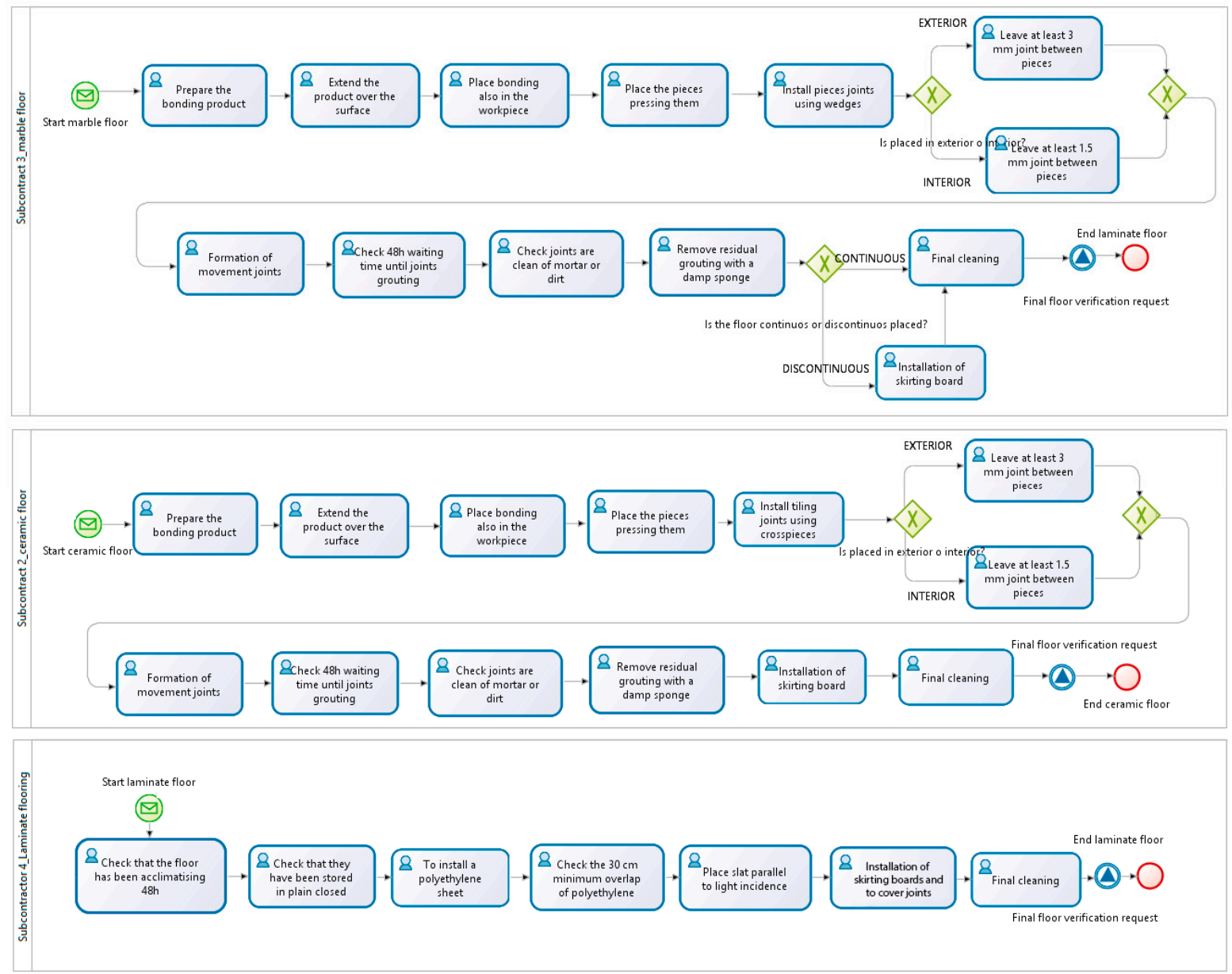

Figure 9. Flooring process BPMN model. 
The process modeling has allowed us to achieve the following principles and their associated benefits:

- Standardization. It is a Lean principle that is increased with its realization by a standard modeling easily understandable by any role of the organization and based on a formal language that enables its automation. In both processes it will allow to stakeholders know what to do, how and by whom. Furthermore, in the case of the flooring, it has been done a redesign of the processes as a good practice based on the different techniques recommendations and the experience of several site managers.

- Another important aspect is the principle of processes composition in which BPMN is based. Modifications or link some processes with others is a very agile task that allows changing the behavior of a process in minutes. Any anomaly in the process could be rectified in a very short space of time, reducing the number of errors by the same problem. Furthermore, each subcontractor could include its own modeled processes, facilitating the integration and incorporation of its system with the one of the builder. Another Lean principle that is facilitated thanks to the use of BPM.

- In this first phase of modeling, another important Lean principle that has allowed implement Bonita BPM, is the tack time. The tack time is the time required to perform a task depending on the time available for the entire process. To determine this time is essential to control more accurately the progress of the work execution. In fact, as we shall see, automatically we will get information in real time about what tasks are not being done on time, which can help the site manager to identify problems early.

From the process modeling has been done the implementation of each of the tasks that compose the process, with particular emphasis on the needs of usability and accessibility in the built environment.

Firstly it has been developed a very flexible software tool that implements the Weekly Work Plan Process, till now performed manually. The entry point of this process is an event that is automatically launched every week, notifying everyone involved that must be met for the weekly schedule. This meeting could be virtual since they share a collaborative environment (Figure 10), involving considerable savings with respect to traditional methods. This planning is done starting from the tasks to be performed according to the 6 Weeks Look Ahead Schedule process. The environment implements a canvas and sticky's metaphor and includes a panel which allows using a simple drag and drop process to distribute tasks during the week, assign actors and specify the location where it must be carried out. At all times the user will have visual aids that reflect the state of the task.

Each task has an associated BPM process that establishes how to be executed and marks the execution time of the task from the tack time of each of the component tasks. Once planning is closed, the site manager can launch the process associated to each task, allowing the beginning of the execution of construction processes. In the tool these activities shall include a mark on the image that represents the task, enabling visualization at any time and from any location and device.

As shown in the Figure 10, for the same day of the week, Monday, it has been planned different types of floor to be executed. The execution of each process starts a series of events that would notify to the responsible of the tasks what to do together with the additional information for its management. These are human tasks, so to integrate the workers with the system devices have been used to facilitate interaction, offering a friendly, usable and simple interface. In this case we have done a prototype using 
platforms such us a smartwatch and a smartphone, as is shown in Figure 11. As the operator is carrying out the tasks, the processing sequence is advanced. The task management is very simple, is focused on reporting the task to be done, to execute the basic actions of it (start, stop, validation, etc....).

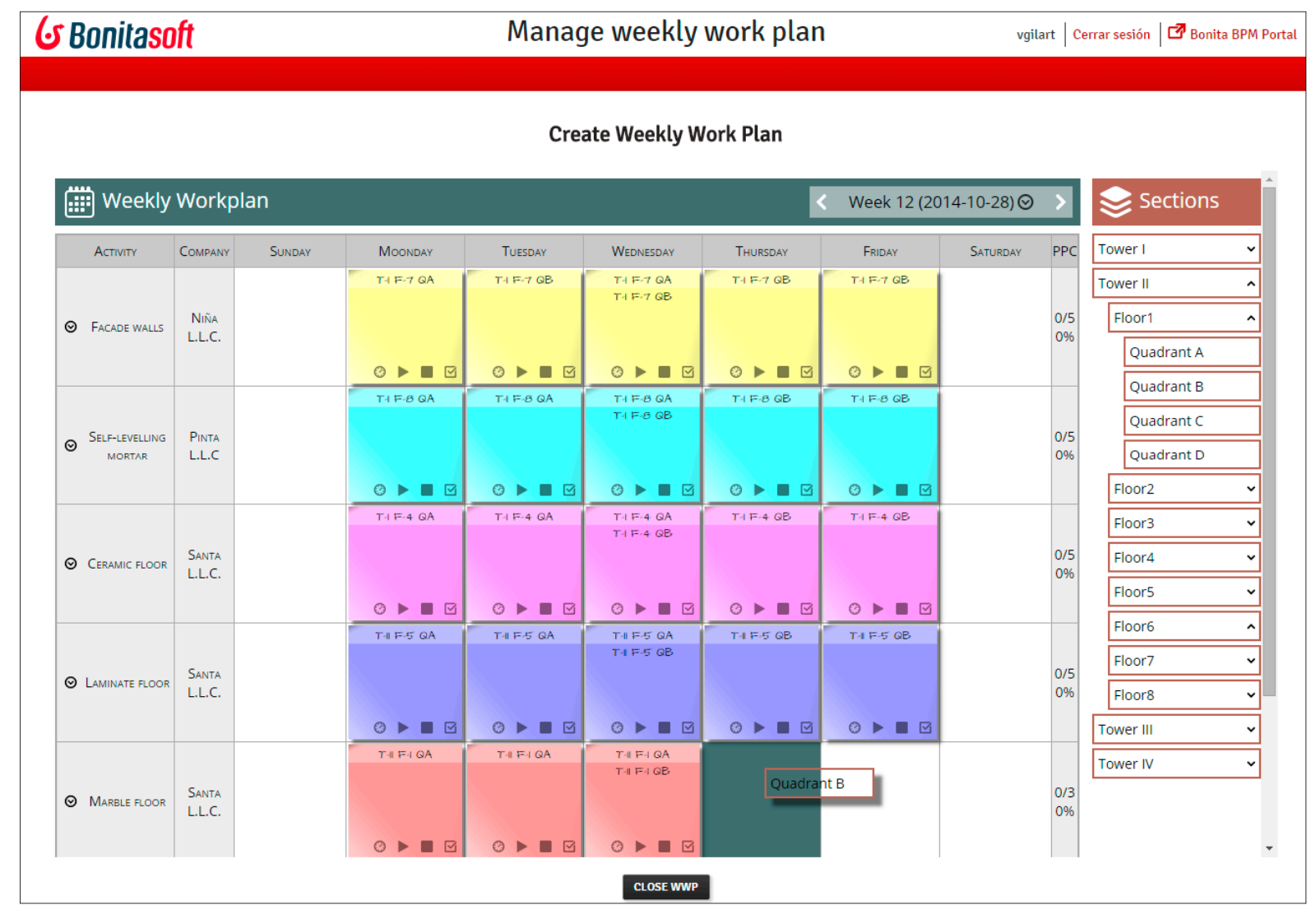

Figure 10. Screenshot of Weekly Work Plan application embedded in Bonita BPM Plannig phase.

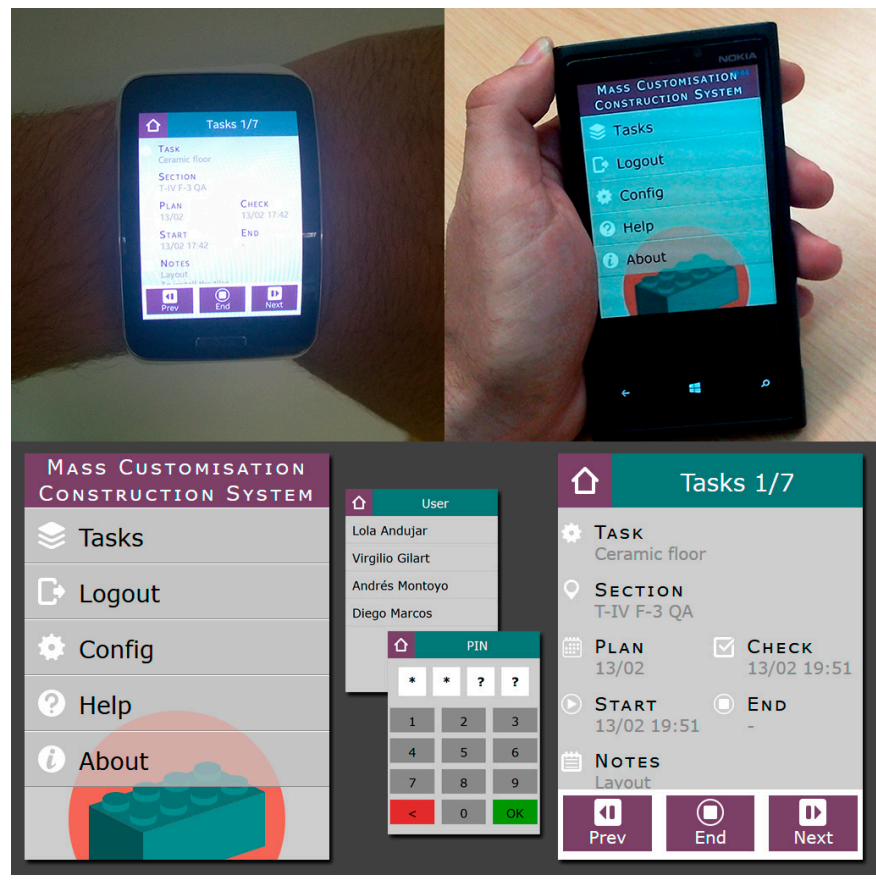

Figure 11. User agent for system interaction. Smartwatch and smartphone versions and interface screenshots. 
Once a task is closed, the system notifies the next task to the appropriate worker. When the closure of a task involves the completion of a process, such action will be reflected in the application the Weekly Work Plan, showing the image of the task with a cross over it (Figure 12). Before starting a task, an operator can validate that the above task has been completely finished. This action involves, in the terminology of the weekly work plan, a double strikethrough on the visual representation of the task and updating the Percent Plan Completed (PPC) (Figure 12).

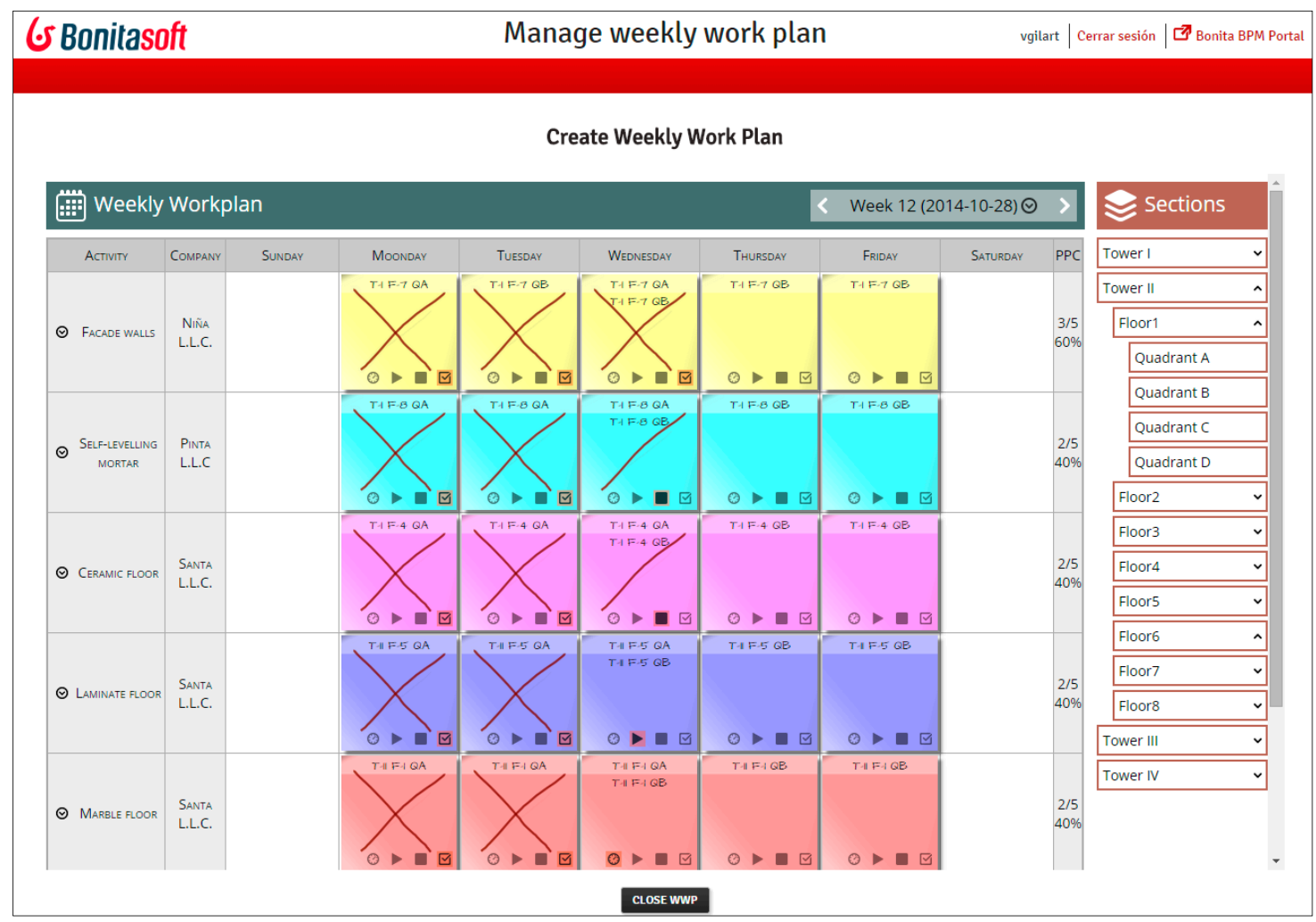

Figure 12. Screenshot of Weekly Work Plan application embedded in Bonita BPM. Traceability phase.

The implementation involves achieving the following principles, as is shown above in Figure 7, and its associated benefits to achieve the objectives of the proposal:

Automation. This is one of the BPM fundamentals, which allows the organization to automate the implementation, monitoring and control of its processes through the orchestration and integration of Processes, systems, people and information to create uniform, streamlined, and repeatable Business Processes. This automation is based on a process-centric approach where automation is performed on a redesign of the process based on best practices. Its automation implies an increase in performance in the process execution and therefore greater efficiency and productivity. Furthermore, the use of everyday devices based on IoT paradigm, in our case connected via Rest Services to the process facilitates the integration of human people in the same, allowing interaction and improving the efficiency and integration. Finally, it has been automated through events the notifications of tasks and actions to guide workers in the development of their activities. All this has led to improve the understanding and learning of the methodologies, techniques and philosophies implemented. Information available in real time and ubiquity. The proposal allows access to the state of the building process at any time, allowing each 
member involved to have complete information about it. Furthermore, such information can be consulted from any location and computer devices (pc's, laptops, tables, smartphones and wareables). This means saves on the time execution and therefore cost, also reductions of errors due to lack of information.

Communication, coordination and transparency. As was mentioned before, both the general framework of Bonita BPM and the applications developed on it, have been implemented in a collaborative work environment which together with the above principles of availability and ubiquity, enable synchronization and coordination of all stakeholders, which achieves the objectives of efficiency and productivity and integration. Traceability and monitoring. On one hand, the implementation of the Weekly Work Plan application allows for a visual feedback of the coarse-grained tasks. The automation of processes in Bonita BPM provides us full traceability and monitoring on the execution and the status of tasks, the time taken for completion, the person responsible who performed it and the task information that has been added. The level of detail provided is fine grained which will allow the site manager and work teams more precise control about each task. In this way it is possible to detect in real time the deviations of daily, and weekly planning and longer term planning the tack time defined (Figure 13). In fact, the system notifies the responsible any deviation on the tack time. All this information can be accessed from anywhere with different devices representing a complete knowledge about the execution of the work that influences in productivity, efficiency, and together with the composition, agile change management.

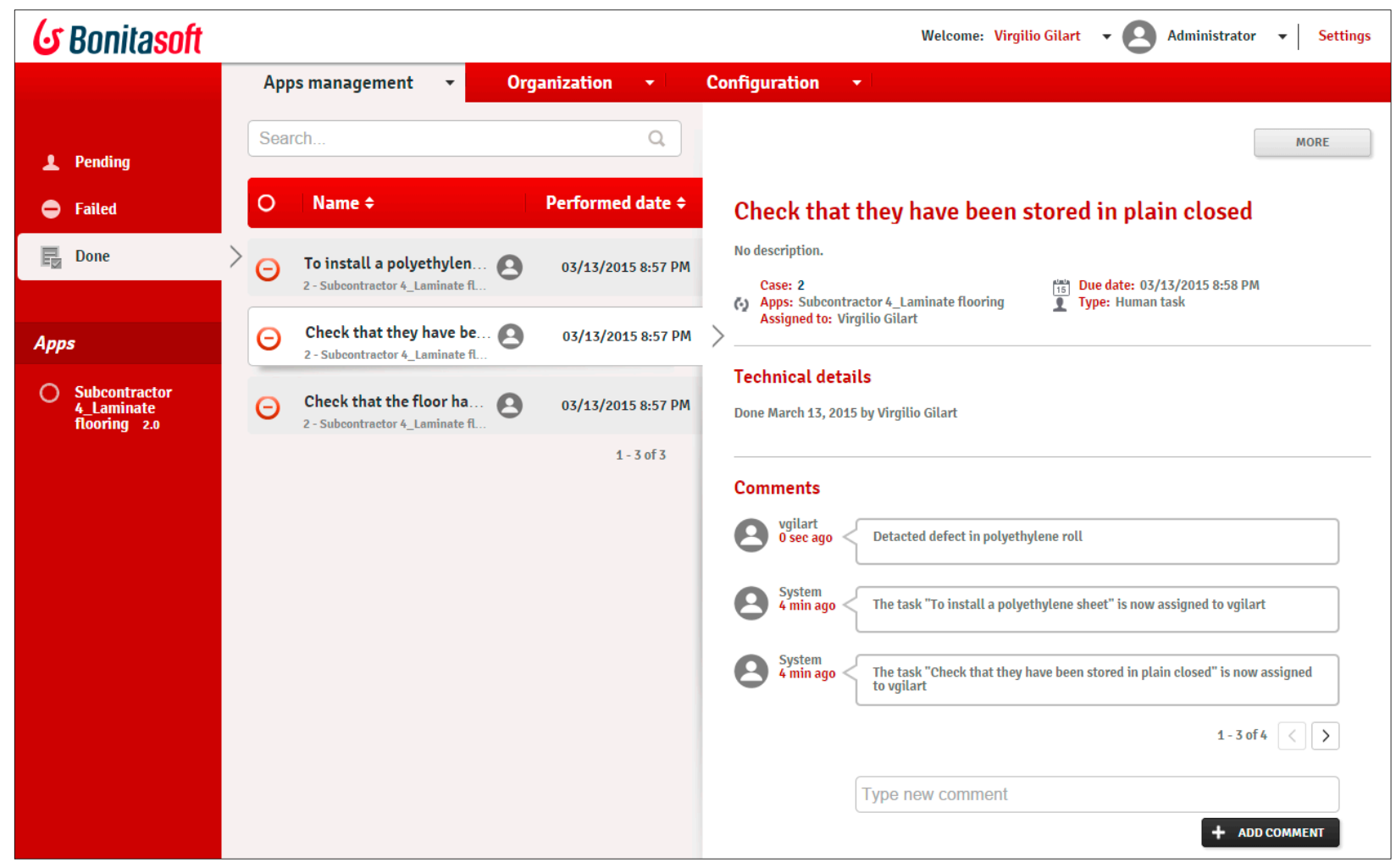

Figure 13. Bonita portal screenshot. Traceability and monitoring of flooring process.

\section{Conclusions, Contributions and Future Work}

In this paper we have presented a theoretical model for managing the execution of the work aimed at achieving carry out mass customization paradigm in traditional construction. 
We have implemented a prototype model which has allowed showing its viability and has highlighted how the implementation of a representative set of techniques achieve the objectives of mass customization such as efficiency, productivity, agility and change management integration.

The main contributions of this work can be summarized in:

- It is the first time that BPM is applied to the field of construction in general, and the execution of the works, in particular. BPM allows achieving the principles of standardization, automation, agility, flexibility, integration. On the other hand, it is a generic framework that allows brings together and promotes the benefits of other strategies and to align management philosophies to align with information technology.

- It has been done an integral management model for mass customization in the execution of the work, particularly for traditional construction from the current management models.

- It has been carried out an integration of Lean and BPM paradigms; in particular, it has been automated using Bonita BPM a part of the Last Planner process (Weekly Work Plan). Until now there were some theoretical proposals offering the synergy benefits of these strategies, but none of them are focused on the specific area of construction.

- It has been incorporated everyday items based on the paradigm IoT to facilitate the integration of the construction actors in the process automation. Due to the characteristics of the work environment, have been selected devices such as wareables with transparency features, usability, flexibility and accessibility.

- A redesign and standardization of the flooring process has been presented through the BPMN modelling language.

Currently, we are working on the implementation of new processes and modules of the proposed model, including Six Sigma strategy, in order to include them in the present approach.

Over this implementation, as future lines of work, we are going to develop an ontology of the building execution standard core processes, allowing the dynamic and automatic generation of the full process from customer's choices. In addition, this study is considered the first step to derive a global model that integrates the entire value chain for the construction, from the design stage to the delivery of the property.

\section{Acknowledgments}

This work was supported in part by the Vicerrectorado de Investigación, Desarrollo e Innovación, University of Alicante and by the Conselleria d'Educació, Cultura i Esport, Generalitat Valenciana.

\section{Author Contributions}

Virgilio Gilart-Iglesias and Andrés Montoyo are the Directors of the research in which all authors have contributed. María Dolores Andújar-Montoya has made the conceptualization and the problem definition, and together with Virgilio Gilart-Iglesias and Andrés Montoyo all they have developed the proposed model. Likewise, the designing of the system and its validation has been carried out by Virgilio Gilart-Iglesias, Diego Marcos-Jorquera and Maria Dolores Andújar-Montoya. The four authors wrote the paper, revised, read and approved the final manuscript. 


\section{Conflicts of Interest}

The authors declare no conflict of interest.

\section{References}

1. Bernard, A.; Daaboul, J.; Laroche, F.; da Cunha, C. Mass customisation as a competitive factor for sustainability. In Enabling Manufacturing Competitiveness and Economic Sustainability, Proceedings of the 4th International Conference on Changeable, Agile, Reconfigurable and Virtual Production, Montreal, QC, Canada, 2-5 October, 2011; Springer: Montreal, QC, Canada, 2012; pp. 18-25.

2. Pine, B.J. Mass Customization: The New Frontier in Business Competition; Harvard Business School Press: Boston, MA, USA, 1999.

3. Tseng, M.M.; Hu, S.J. Mass customization. In Cirp Encyclopedia of Production Engineering; Laperrière, L., Reinhart, G., Eds.; Springer: Berlin, Germany, 2014; pp. 836-843.

4. Tseng, M.M.; Jiao, J.; Merchant, M.E. Design for mass customization. CIRP Ann.-Manuf. Technol. 1996, 45, 153-156.

5. Confederación Nacional de la Construcción (CNC). Informe de Evolución del Sector de la Construcción; National Confederation of Construction: Madrid, Spain, 2011; pp. 17-46.

6. Gilmore, J.H.; Pine, B.J. Authenticity: What Consumers Really Want; Harvard Business School Press: Boston, MA, USA, 2007; Volume 1.

7. Barlow, J. From craft production to mass customisation? Customer focused approaches to house building. In From Craft Production to Mass Customisation? Customer Focused Approaches to House Building, Proceedings of IGLC 6th Annual Conference, Sao Paulo, Brazil, 13-15 August 1998; Citeseer: Sao Paulo, Brazil, 1998.

8. Nambiar, A.N. Mass customization: Where do we go from here? In Mass Customization: Where do We Go from Here? Proceedings of the World Congress on Engineering WCE, London, UK, 1-3 July 2009; pp. 1-3.

9. Piller, F.T.; Moeslein, K. From economies of scale towards economies of customer integration: Value creation in mass customization based electronic commerce. In Proceedings of the 15th Bled Electronic Commerce Conference e-Reality: Constructing the e-Economy, Bled, Slovenia, 17-19 June 2002.

10. Radder, L.; Louw, L. Mass customization and mass production. The TQM Mag. 1999, 11, 35-40.

11. Noguchi, M.; Hernàndez-Velasco, C.R. A 'mass custom design' approach to upgrading conventional housing development in Mexico. Habitat Int. 2005, 29, 325-336.

12. Noguchi, M. The "mass custom design" approach to the delivery of quality affordable homes. Available online: http://www.masscustomhome.com/ (accessed on 8 November of 2014).

13. Cuperus, Y. Mass customization in housing, an open building/lean construction study. In Proceedings of Dense Living Urban Structures International Conference on Open Building, Hong Kong, China, 23-26 October 2003; pp. 1-13.

14. Aziz, R.F.; Hafez, S.M. Applying lean thinking in construction and performance improvement. Alexandria Eng. J. 2013, 52, 679-695. 
15. Porter, M.E. Competitive Advantage of Nations: Creating and Sustaining Superior Performance; Simon and Schuster: New York, NY, USA, 2011.

16. Almeida, J.C.; Salazar, G.F. Strategic issues in lean construction. In Proceedings of the 11th Annual Conference of the International Group for Lean Construction, Blacksburg, VA, USA, 22-24 July 2003; pp. 1-10.

17. Ahuja, V.; Yang, J.; Shankar, R. Strategic use of ict by construction organisations-requirements and implementation issues. Bus. Process Manag. J. 2006, 15, 968-989.

18. Rausch, P.; Stumpf, M. Linking the operational, tactical and strategic levels by means of cpm: An example in the construction industry. In Business Intelligence and Performance Management; Rausch, P., Sheta, A.F., Ayesh, A., Eds.; Springer: London, UK, 2013; pp. $27-42$.

19. Cork, R. Is construction ready for project based erp? Available online: http://download.ifsworld.com/ home/if1/page_480/is_construction_ready_for_project_based_erp_yet.html (accessed on 24 April 2015).

20. Chung, B.; Skibniewski, M.J.; Kwak, Y.H. Developing erp systems success model for the construction industry. J. Construct. Eng. Manag. 2009, 135, 207-216.

21. Looy, A.V. Business Process Maturity. A Comparative Study on A Sample of Business Process Maturity Models; Springer International Publishing: Vaduz, Liechtenstein, 2014; Volume 1, p. 87.

22. Willaert, P.; van den Bergh, J.; Willems, J.; Deschoolmeester, D. The process-oriented organisation: A holistic view developing a framework for business process orientation maturity. In Business Process Management; Springer: Berlin, Germany, 2007; pp. 1-15.

23. Harmon, P. Business Process Change: A Guide for Business Managers and Bpm and Six Sigma Professionals; Elsevier/Morgan Kaufmann: Burlington, MA, USA, 2010.

24. Ohtonen, J. Combining all bpm methods-is that possible? Available online: http://www.bpmleader.com/ 2012/07/02/combining-all-bpm-methods-\%E2\%80\%93-is-that-possible/ (accessed on 2 October 2014).

25. Smith, H.; Fingar, P. Business Process Management (BPM): The Third Wave; Meghan-Kiffer Press: Tampa, FL, USA, 2003.

26. Noguchi, M. The effect of the quality-oriented production approach on the delivery of prefabricated homes in Japan. J. Hous. Built Environ. 2003, 18, 353-364.

27. Juan, Y.-K.; Shih, S.-G.; Perng, Y.-H. Decision support for housing customization: A hybrid approach using case-based reasoning and genetic algorithm. Expert Syst. Appl. 2006, 31, 83-93.

28. Lee, S.; Ha, M. Customer interactive building information modeling for apartment unit design. Autom. Construct. 2013, 35, 424-430.

29. Benros, D.; Duarte, J. An integrated system for providing mass customized housing. Autom. Construct. 2009, 18, 310-320.

30. Shin, Y.; An, S.-H.; Cho, H.-H.; Kim, G.-H.; Kang, K.-I. Application of information technology for mass customization in the housing construction industry in Korea. Autom. Construct. 2008, 17, 831-838.

31. Gilart-Iglesias, V. Metodología para la gestión integral de los procesos de producción: Modelado de la maquinaria industrial como un sistema de gestión de procesos de negocio. Ph.D. Thesis, Polytechnic University College, University of Alicante, Alicante, Spain, 2010. 
32. Gilart-Iglesias, V.; Maciá-Pérez, F.; Marcos-Jorquera, D.; Mora-Gimeno, F.J. Industrial machines as a service: Modelling industrial machinery processes. In Proceedings of the 2007 th IEEE International Conference on Industrial Informatics, Wien, Austria, 23-27 June 2007; pp. 737-742.

33. Ferrándiz Colmeiro, A.; Maciá Pérez, F.; Gilart Iglesias, V.; Berná Martínez, J.V.; Gea Martínez, J. Automatización del modelado y gestión de procesos de fabricación dirigida por semántica. In Proceedings of VI Jornadas para el Desarrollo de Grandes Aplicaciones de Red (JDARE'09), Alicante, Spain, 2009; pp. 181-198.

34. Penker, M.; Eriksson, H.-E. Business Modeling With UML: Business Patterns at Work. Available online: http://dsc.ufcg.edu.br/ sampaio/Livros/Wiley-Business-Modeling-with-UML-Business-Patternsat-Work.pdf (accessed on 24 April 2015).

35. ISEA. La innovación, una prioridad para el sector de la construcción. Available online: http://www.iseamcc.net/news/revista/revista-isea-03.pdf (accessed on 13 October 2014).

36. Cuadrado-Roura, J. El sector de la Construcción en España: Análisis, Perspectivas y Propuestas; Cuadernos del Colegio Libre de Eméritos: Madrid, Spain, 2010. Available online: http://www.colegiodeemeritos.es/docs/repositorio/es_ES/Cuadernos_del_Colegio/el_sector_const ruccion_en_espana_\%28final\%29.pdf (accessed on 13 October 2014).

37. Bakar, A.H.A.; Tufail, M.A.; Yusof, M.N.; Pinang, W.M.; Virgiyanti, W. Implementation of strategic management practices in the malaysian construction industry. Pak. J. Commer. Soc. Sci. 2011, 5, 140-154.

38. Price, A.; Newson, E. Strategic management: Consideration of paradoxes, processes, and associated concepts as applied to construction. J. Manag. Eng. 2003, 19, 183-192.

39. Vicedo, J.C.; Pérez, A.H.; Esteban, F.C.L. Análisis de adaptación al sector de la construcción de estructuras organizativas y de producción existentes en el sector del automóvil. In Proceedings of V Congreso de Ingeniería de Organización: Valladolid-Burgos, Spain, 4-5 September 2003.

40. Martín, A.I.F.; Frías, V.G.; Romero, B.P. La cadena de suministro en proyectos de construcción. In Proceedings of the II International Conference on Industrial Engineering and Industrial Management, Burgos, Spain, 3-5 September 2008; pp. 1715-1724.

41. Arcudia Abad, C.E.; Solís Carcaño, R.G.; Baeza Pereyra, J.R. Determinación de los factores que afectan la productividad de la mano de obra de la construcción. Ingeniería 2004, 8, 145-154.

42. Giménez Palavicini, Z.; Suárez Isea, C. Diagnóstico de la gestión de la construcción e implementación de la constructabilidad en empresas de obras civiles. Revista Ingeniería de Construcción 2008, 23, 4-17.

43. Chiang, Y.-H.; Tang, B.-S. "Submarines don't leak, why do buildings?" Building quality, technological impediment and organization of the building industry in hong kong. Habitat Int. 2003, $27,1-17$.

44. Ontsi, F.Y.E. Análisis sectorial de implantación de las tic en la pyme española. Available online: http://www.ipyme.org/Publicaciones/InformePyme2013.pdf (accessed on 17 October 2014).

45. Shi, J.J.; Halpin, D.W. Enterprise resource planning for construction business management. J. Construct. Eng. Manag. 2003, 129, 214-221.

46. Yang, J.-B.; Wu, C.-T.; Tsai, C.-H. Selection of an erp system for a construction firm in Taiwan: A case study. Autom. Construct. 2007, 16, 787-796. 
47. Forcada Matheu, N. Life Cycle Document Management System for Construction. Ph.D. thesis, Polytechnic University of Catalonia, University of Catalonia, Catalonia, Spain, 2005.

48. Cembellín, B.H. Herramientas informáticas para construir y fabricar. Técnica Industrial 2009, 283, 36-39.

49. Alshawi, M.; Faraj, I. Integrated construction environments: Technology and implementation. Constr. Innov.: Inf. Process Manag. 2002, 2, 33-51.

50. Alshawi, M.; Ingirige, B. Web-enabled project management: An emerging paradigm in construction. Autom. Construct. 2003, 12, 349-364.

51. Hong-Minh, S.; Barker, R.; Naim, M. Identifying supply chain solutions in the uk house building sector. Eur. J. Purch. Supply Manag. 2001, 7, 49-59.

52. Ballard, G.; Howell, G. Implementing lean construction: Stabilizing work flow. Available online: http://www.leanconstruction.dk/media/18181/Implementing_Lean_Construction_Stabilizing_W ork_Flow_.pdf (accessed on 24 April 2015).

53. Smith, N.J.; Merna, T.; Jobling, P. Managing risk in Construction Projects; John Wiley \& Sons: Oxford, UK, 2013.

54. Koskela, L. Application of the New Production Philosophy to Construction; Technical Report No. 72; Stanford University: Stanford, CA, USA, 1992.

55. Koskela, L. Lean production in construction. Available online: http://www.iaarc.org/publications/ fulltext/Lean_production_in_construction.PDF (accessed on 24 April 2015).

56. Leavitt, H.J. Applied organizational change in industry: Structural, technical and human approaches. In New Perspective in Organization Research; Cooper, W.W., Leavitt, H.J., Shelly, M.W., II, Eds.; Wiley: New York, NY, USA, 1964; Volume 55, p. 71.

57. Orozco, F.A.; Serpell, A.F.; Molenaar, K.R.; Forcael, E. Modeling competitiveness factors and indexes for construction companies: Findings of Chile. J. Construct. Eng. Manag. 2011, 140, 1-13.

58. Egan, S. J.; Williams, D. Rethinking construction: The report of the construction task force. Available online: http://constructingexcellence.org.uk/wp-content/uploads/2014/10/rethinking _ construction_report.pdf (accessed on 28 September 2014).

59. Newman, M.; Zhao, Y. The process of enterprise resource planning implementation and business process re-engineering: Tales from two chinese small and medium-sized enterprises. Inform. Syst. J. 2008, 18, 405-426.

60. Love, P.E.; Irani, Z. An exploratory study of information technology evaluation and benefits management practices of SMEs in the construction industry. Inf. Manag. 2004, 42, 227-242.

61. Sexton, M.; Barrett, P.; Miozzo, M.; Wharton, A.; Leho, E.; Hughes, W. Innovation in small construction firms: Is it just a frame of mind? In Proceedings of 17th Annual ARCOM Conference, Salford, UK, 5-7 September 2001.

62. Womack, J.P.; Jones, D.T. Lean Thinking: Banish Waste and Create Wealth in Your Corporation; Simon and Schuster: New York, NY, USA, 2010.

63. Howell, G.A. What is lean construction-1999. In Proceedings of Seventh Annual Conference of the International Group for Lean Construction, IGLC-7, Berkeley, CA, USA, 26-28 July 1999; pp. $1-10$. 
64. Abdelhamid, T.S.; Everett, J.G. Physical demands of construction work: A source of workflow unreliability. In Proceedings of the 10th Conference of International Group for Lean Construction IGLC-10, Gramado, Brazil, 6-8 August 2002.

65. Oguz, C.; Kim, Y.-W.; Hutchison, J.; Han, S. Implementing lean six sigma: A case study in concrete panel production. In Proceedings of the 20th Annual Conference of the International Group for Lean Construction IGLC-20, San Diego, CA, USA, 18-20 July 2012

66. Abdelhamid, T.S. Six Sigma in Lean Construction Systems: Opportunities and Challenges. In Proceedings of the Eleventh Annual Conference of the International Group for Lean Construction IGLC-11, Blacksburg, VA, USA, 22-24 July 2003.

67. Han, S.H.; Chae, M.J.; Im, K.S.; Ryu, H.D. Six sigma-based approach to improve performance in construction operations. J Manag Eng 2008, 24, 21-31.

68. Pheng, L.; Hui, M. Implementing and applying six sigma in construction. J Construct Eng Manag 2004, 130, 482-489.

69. Tutesigensi, A.; Pleim, V. Title of Presentation. In Why Small and Medium Construction Enterprises do not Employ Six Sigma, Proceedings of 24th Annual ARCOM Conference, Cardiff, UK, 1-3 September 2008; pp. 267-276.

70. Tchidi, M.F.; He, Z.; Li, Y.B. Process and quality improvement using six sigma in construction industry. J. Civ. Eng. Manag. 2012, 18, 158-172.

71. Shan, Y.-H.; Li, Z.-F. Integration and application of lean principles and six sigma in residential construction. In Proceedings of 2012 3rd International Asia Conference on Industrial Engineering and Management Innovation. Available online: http://link.springer.com/chapter/10.1007/978-3642-33012-4_25 (accessed on 25 April 2015).

72. Banawi, A.; Bilec, M.M. A framework to improve construction processes: Integrating lean, green and six sigma. Int. J. Constr. Manag. 2014, 14, 45-55.

73. Sunil, V.D.; Sharad, V.D. Minimising waste in construction by using lean six sigma principles. Int IJCIET 2013, 4, 1-8.

74. George, M.L.; George, M. Lean Six Sigma for Service; McGraw-Hill: New York, NY, USA, 2003.

75. Visser, B. Lean principles in case management. Master's Thesis, Radboud Universiteit, Nijmegen, The Netherland, 2009.

76. Chiarini, A. Discussion and comparison about the common characteristics. In From Total Quality Control to Lean Six Sigma; Springer: Milan, Italy, 2012; pp. 47-51.

77. Chen, Q.; Reichard, G.; Beliveau, Y. Interface management-A facilitator of lean construction and agile project management. Proceedings of the 15th Annual Conference of the IGLC 15, 18-20 July 2007, East Lansing, MI, USA; pp. 57-66.

78. Erl, T. Service-Oriented Architecture: Concepts, Technology, and Design; Pearson Education Crwafordsville: Indiana, IN, USA, 2005.

79. Erl, T. Soa Design Patterns; Pearson Education: Boston, MA, USA, 2008.

80. Marks, E.A.; Bell, M. Service Oriented Architecture (SOA): A Planning and Implementation Guide for Business and Technology; John Wiley \& Sons: Hoboken, NJ, USA, 2006.

81. Morris, D.; Field, G. BPM, lean and six sigma better together the whole is greater than the sum of the parts. Available online: http://c.ymcdn.com/sites/www.abpmp.org/resource/resmgr/Docs/ news_events_bpm_lean_6.pdf (accessed on 25 April 2015). 
82. Jeston, J.; Nelis, J. Business Process Management; Elsevier Butterworth Heinemann: Burlington, MA, USA, 2014.

83. Woodley, T.; Gagnon, S. BPM and SOA: Synergies and challenges. In Web Information Systems Engineering-Wise 2005. 6th International Conference on Web Information Systems Engineering; Springer: New York, NY, USA, 2005; pp. 679-688.

84. Kirchmer, M. High Performance through Process Excellence: High Performance through Process Excellence; Springer-Verlag: Berlin, Germany, 2009.

85. Zur Muehlen, M.; Ho, D.T.-Y. Risk management in the bpm lifecycle. In Business Process Management BPM 2005 Workshops; Springer-Verlag: Berlin, Germany, 2006, pp. 454-466.

86. Chang, J.F. Business Process Management Systems: Strategy and Implementation; Auerbach Publications: Boca Raton, FL, USA, 2005.

87. Barros, O. Business processes architecture and design. Bus. Process Trend 2007, 1, 1-28.

(C) 2015 by the authors; licensee MDPI, Basel, Switzerland. This article is an open access article distributed under the terms and conditions of the Creative Commons Attribution license (http://creativecommons.org/licenses/by/4.0/). 